\title{
Estimated macronutrient and fatty acid intakes from an East African Paleolithic diet
}

\author{
Remko S. Kuipers $^{1 *}$, Martine F. Luxwolda ${ }^{1}$, D. A. Janneke Dijck-Brouwer ${ }^{1}$, S. Boyd Eaton ${ }^{2}$, \\ Michael A. Crawford ${ }^{3}$, Loren Cordain $^{4}$ and Frits A. J. Muskiet ${ }^{1}$ \\ ${ }^{1}$ Department of Laboratory Medicine, University Medical Center Groningen (UMCG), University of Groningen, \\ PO Box 30.001, 9700 RB, Groningen, The Netherlands \\ ${ }^{2}$ Departments of Anthropology and Radiology, Emory University, Atlanta, GA, USA \\ ${ }^{3}$ Department of Bio-molecular Medicine, Imperial College, London, UK \\ ${ }^{4}$ Department of Health and Exercise Science, Colorado State University, Fort Collins, CO, USA
}

(Received 3 February 2010 - Revised 17 May 2010 - Accepted 18 May 2010 - First published online 23 September 2010)

Our genome adapts slowly to changing conditions of existence. Many diseases of civilisation result from mismatches between our Paleolithic genome and the rapidly changing environment, including our diet. The objective of the present study was to reconstruct multiple Paleolithic diets to estimate the ranges of nutrient intakes upon which humanity evolved. A database of, predominantly East African, plant and animal foods (meat/fish) was used to model multiple Paleolithic diets, using two pathophysiological constraints (i.e. protein $<35$ energy $\%$ (en\%) and linoleic acid (LA) $>1.0$ en\%), at known hunter-gatherer plant/animal food intake ratios (range 70/30-30/70 en\%/en\%). We investigated selective and non-selective savannah, savannah/aquatic and aquatic hunter-gatherer/scavenger foraging strategies. We found (range of medians in en\%) intakes of moderate-to-high protein (25-29), moderate-to-high fat (30-39) and moderate carbohydrates (39-40). The fatty acid composition was SFA (11.4-12.0), MUFA (5.6-18.5) and PUFA (8.6-15.2). The latter was high in $\alpha$-linolenic acid (ALA) (3.7-4.7 en\%), low in LA (2.3-3.6 en\%), and high in long-chain PUFA (LCP; 4.75-25.8 g/d), LCP $n-3$ (2.26-17.0 g/d), LCP $n-6$ (2.54-8.84 g/d), ALA/LA ratio $(1.12-1.64 \mathrm{~g} / \mathrm{g})$ and LCP $n-3 / \mathrm{LCP} n-6$ ratio $(0 \cdot 84-1.92 \mathrm{~g} / \mathrm{g})$. Consistent with the wide range of employed variables, nutrient intakes showed wide ranges. We conclude that compared with Western diets, Paleolithic diets contained consistently higher protein and LCP, and lower LA. These are likely to contribute to the known beneficial effects of Paleolithic-like diets, e.g. through increased satiety/satiation. Disparities between Paleolithic, contemporary and recommended intakes might be important factors underlying the aetiology of common Western diseases. Data on Paleolithic diets and lifestyle, rather than the investigation of single nutrients, might be useful for the rational design of clinical trials.

Paleolithic diet: Land-water ecosystem: Hunter-gatherers: Evolutionary medicine: Macronutrients: Arachidonic acid: Linoleic acid: $\alpha$-Linolenic acid: Docosahexaenoic acid: Cholesterol: Long-chain PUFA

Our genome is the product of millions of years of evolution in which it slowly adapted to ensure reproductive success under the environmental selective pressures imposed upon our species $^{(1)}$. Evolutionary medicine predicts that many complex degenerative diseases originate from unfavourable changes in our environment that, in the light of our long generation time, are too rapid to cause appropriate adaptation of our slowly adapting genome ${ }^{(2)}$. Such genetic adaptations are also unlikely to occur, since these unfavourable changes exert little selection pressure. That is, they do not cause death before reproductive age, but rather reduce years in health at the end of the life cycle ${ }^{(1,3)}$. Our, nevertheless, increased life expectancy originates mostly from technological achievements (e.g. the introduction of public health sanitation, the prevention of (childhood) infections, famine, homicide and tribal warfare $)^{(4)}$, which diminish the influence of certain unfavourable conditions of existence. Since the agricultural revolution (some 10000 years ago) and notably since the industrial revolution (some 200 years ago), we have introduced numerous unfavourable changes into our environment and lifestyle. These factors include changes in diet, physical activity, stress, sleep duration and environmental pollution among others. Important dietary and environmental changes, especially in affluent countries, that may adversely affect health and well-being include a decreased $n-3 / n-6$ fatty acid ratio, combination of high intakes of SFA and carbohydrates $^{(5)}$, introduction of industrially produced trans fatty acids, reduced exposure to sunlight, lower intakes of vitamins $\mathrm{D}$ and $\mathrm{K}$, imbalanced intake of antioxidants, high intakes of carbohydrates with high glycaemic indices and loads, and little dietary fibre. Together, with a sedentary lifestyle, these dietary alterations gave rise to an unprecedented body composition characterised by increased fat mass and sarcopenia ${ }^{(6)}$. These culturally driven environmental changes have exceeded

Abbreviations: AA, arachidonic acid; ALA, $\alpha$-linolenic acid; en\%, energy \%; LA, linoleic acid; LCP, long-chain PUFA; RCT, randomised controlled trials. 
the flexibility of our epigenotype to adapt and have resulted in a maladapted phenotype, primarily after reproductive age.

It has been hypothesised ${ }^{(1)}$ that the range of optimal nutrient combinations to support good health are present in the foods that were consumed by our Paleolithic ancestors who were living from 2.5 million to 10000 years ago. Their diets and environment represent the selective pressures under which our genome evolved. The fish oil fatty acids EPA and DHA (and their derivatives), vitamin D (1,25-dihydroxyvitamin D) and vitamin A (retinoic acid) are examples of nutrients that act in concert, while each of these has multiple actions ${ }^{(7,8)}$. Consequently, the criteria for establishing optimum nutrient intakes via randomised controlled trials (RCT) with single nutrients at a given dose and with a single end point have serious limitations. They are usually based upon poorly researched dose-response relationships, and typically ignore many possible nutrient interactions and metabolic interrelationships. For instance, the adequate intake of linoleic acid (LA) to prevent LA deficiency depends on the concurrent intakes of $\alpha$-linolenic acid (ALA), $\gamma$-LA and arachidonic acid (AA). Consequently, the nutritional balance on which our genome evolved is virtually impossible to determine using the reigning paradigm of 'evidence-based medicine' with RCT. Nutritional research rather needs an organisational template that focuses on the optimal homeostasis. This template may be obtained from the reconstruction of Paleolithic diets. Disparity between the range of nutrients found in the current Western diet and reconstructed Paleolithic diets will provide a direction for guiding future dietary interventions.

The composition of Paleolithic diets may be derived from many disciplines, including biology, archaeology, anthropology, comparative anatomy, genetics, food science and (patho)physiology. For instance, the sites at which the fossil remains of our hominin ancestors have been discovered suggest that the evolution to anatomically modern humans took place in a long-chain $n-3$ fatty acid-rich diet in an East African land-water ecosystem ${ }^{(9-12)}$. Additionally, the last Out-of-Africa diaspora, starting some 100000 years ago, largely took place via the coastal lines ${ }^{(13)}$, including crossing to the Americas via the Bering Strait ${ }^{(14)}$. Compared with hunting in the savannah, obtaining food from these ecosystems is relatively easy, and the foods are rich in haeme $\mathrm{Fe}$, iodine, $\mathrm{Zn}, \mathrm{Cu}$, Se, vitamins $\mathrm{A}$ and $\mathrm{D}$, and $n-3$ fatty acids from both vegetables and fish, which are collectively referred to as 'brain-selective nutrients' ${ }^{(15,16)}$. Epidemiological data as well as landmark trials with $n-3$ fatty acid consumption or fish consumption demonstrated favourable outcomes for $\mathrm{CHD}^{(17-19)}$, (postpartum) depression ${ }^{(20,21)}$, homicide mortality ${ }^{(21)}$ and neurodevelopment ${ }^{(22)}$. The importance of dietary long-chain PUFA (LCP) is also supported by the low capability to synthesise LCP during the entire life cycle ${ }^{(23)}$, suggesting that ancestral human intakes of AA, EPA and DHA were sufficient for survival and reproductive success. The recently discovered polymorphisms ${ }^{(24)}$ of fatty acid desaturases 1 (FADS1, also named $\Delta 5$-desaturase) and 2 (FADS2, $\Delta 6$-desaturase), with lower activities in their conversion of ALA and LA to LCP, add to the notion that at the time of the first occurrence of these mutations, intakes of dietary LCP compensated for the concomitantly lower LCP synthesis.

Eaton et al. ${ }^{(1,3,25,26)}$ were the first to reconstruct a Paleolithic diet. They assumed a savannah-type diet with non-selective consumption of animals, implying that all the available organs were consumed. This model was further refined by Cordain et al. ${ }^{(27,28)}$, who assumed a savannah diet with multiple subsistence ratios and an 'optimal foraging' strategy. 'Optimal foraging' assumes the preferred consumption of energy-dense foods ${ }^{(28-30)}$ (e.g. by the selective consumption of plants with high fat percentages and the selective consumption of energy-dense animal organs, such as brain and bone marrow). Compared to contemporary intakes, both the models ${ }^{(26-28)}$ suggested lower carbohydrate and higher intakes of protein and LCP. None of the earlier models separately evaluated food intake from the land-water ecosystem, which is the presumed niche of our ancestors ${ }^{(9-11,13,14)}$ and an abundant source of EPA and DHA.

We estimated the dietary macronutrient (carbohydrate, protein and fat) and fatty acid compositions for four foraging strategies ascribed to Paleolithic hunter-gatherer/scavengers who foraged in the savannah (Model 1), a land-water ecosystem (Model 4) and a combination of both (Models 2 and 3). The aim was to determine the composition and range of dietary macronutrients and fatty acids under which the human genome evolved, and which would likely support modern day health and well-being. In contrast to Eaton et al. ${ }^{(26)}$, our modelling of the savannah diet assumed selective consumption of organs, and when compared to the savannah diet as used by Cordain et al. ${ }^{(28)}$, we additionally varied the contributions from muscle, marrow and brain. Our purely aquatic foraging strategy (Model 4) has not been previously evaluated. For the reconstruction, we differentiated between selective (Models 1 and 3) and non-selective (Models 2 and 4) consumption of meat. Within each model, we varied the plant/ animal subsistence ratios, the meat/fish ratios (Models 2 and 3), the fat contents of the plants, meat and fish consumed (Models 2-4) and the muscle/marrow/brain ratios (Models 1 and 3). The final outcome was subjected to certain pathophysiological constraints, since not all the dietary combinations were considered to be compatible with health. In evolutionary terms, health may be defined as an evolutionary fitness to survive up to the reproductive age and beyond for successful reproduction and to take care of the young (the so-called grandmother hypothesis ${ }^{(31,32)}$ ), respectively.

\section{Methods}

\section{Background for the models}

For the calculation of the average macronutrient and fatty acid intakes, we divided the diet into two main components (i.e. plant and animal foods). In contrast to earlier models ${ }^{(26,28)}$, we subdivided the animal food into meat and fish, in which the former was further subdivided into five edible components, namely skeletal muscle, brain, marrow, liver and adipose tissue. Additional organs (e.g. kidney, adrenals, spleen, heart and blood) were considered to be of minor interest. These organs were not included due to limited data on nutrient compositions and a relatively small contribution to overall weight. Since we aimed at investigating the possible ranges of nutrient intakes from multiple Paleolithic diets, we included a wide, but certainly possible, range of variables. In all the models (see below), the plant/animal food ratios in energy \% (en\%) were varied from $70 / 30$ to $30 / 70$ en $\% /$ en $\%$, which is in the 
range of the most commonly observed hunter-gatherer subsistence ratios ${ }^{(26,27)}$. The fat contents by weight $(\mathrm{g} / 100 \mathrm{~g}$ edible material; $\mathrm{g} \%$ ) of all plants, meat and fish were varied from 2.5 to $5 \cdot 0,5.0$ to 30 and 2.5 to $10.0 \mathrm{~g} \%$, respectively, for which justification is given in each particular section below. The information on macronutrient and fatty acid contents of the edible material were obtained from the literature, Internet food databases ${ }^{(33)}$ and our own data. Detailed information on energy and fat contents and the fatty acid compositions of the various foods and their literature references are given in supplementary Table S1 (available online only at http://journals.cambridge.org). Table 1 presents the means, as compiled from these raw data. Using the abovementioned approach, we calculated the outcomes of four different models, representing four foraging strategies ascribed to early Homo genus and assuming a daily energy intake of $12500 \mathrm{~kJ}$.

\section{Description of the models}

Model 1 describes a selective hunter-gatherer/scavenger savannah diet that is composed of plant and animal foods that are effectively available in the savannah, while the consumption of aquatic food was excluded. The employed hard data are in supplementary Table S1 (available online only at http://journals.cambridge.org) and Table 1. 'Selectivity' implies that only the skeletal muscle, marrow and brain were consumed from the animal food, and the liver and adipose tissue were not consumed. The intakes were varied between 98 and 0 en\% (skeletal muscle), 1 and 80 en $\%$ (bone marrow) and 1 and 20 en\% (brain) of the total meat intake. Model 2 describes a non-selective hunter-gatherer/ scavenger savannah/aquatic diet that contains plant and animal foods that are available in the savannah and in an aquatic environment. In accordance with Eaton et al. ${ }^{(26)}$, this model assumes that the whole animal carcass was consumed (i.e. non-selective), including most animal organs, and also the skin and the head in the case of fish. The meat and fish intakes were varied from 100 to 0 and 0 to $100 \mathrm{en} \%$ of total animal consumption, respectively. For calculating the fish intake, we used the energy, fat and fatty acid contents of East African lake and marine fish because of their specific fatty acid compositions ${ }^{(34,35)}$. Model 3 describes a selective hunter-gatherer/scavenger savannah/aquatic diet. This model assumes a diet from aquatic resources and the selective scavenging of muscle, bone marrow and brain from savannah animals. The meat and fish intakes were again varied from 100 to 0 and 0 to $100 \mathrm{en} \%$ of total animal consumption, respectively. In this model, we varied the intakes as muscle, bone marrow and brain from 0 to $50 \mathrm{en} \%$ (muscle), 40 to $80 \mathrm{en} \%$ (bone marrow) and 10 to $20 \mathrm{en} \%$ (brain) of total meat intake. In this model, the fat contents of fish and plant were both set at $5 \mathrm{~g} \%$, while the average fat contents of the combined muscle/marrow/brain in meat varied from 10 to $30 \mathrm{~g} \%$. Model 4 describes a non-selective hunter-gatherer/ scavenger aquatic diet that is composed of plants and fish, while the consumption of meat was not included. Consequently, the fish intakes were $100 \%$ of animal foods in all applied subsistence ratios. The fat content of fish was varied from 2.5 to $10.0 \mathrm{~g} \%$. For calculating the energy, fat and fatty acid content of aquatic foods consumed, we only applied data for East African fish species.

\section{Justification for the models}

The range of the subsistence ratios applied in our models needed an evaluation because of the absence of accurate data on human nutritional (plant/animal en\%/en\%) subsistence ratios in the Paleolithic diets. Unfortunately, plant/animal (en/en\%) subsistence ratios cannot be simply derived from gathering/hunting subsistence ratios. Anthropological studies that differentiate between gathering and hunting often include gathered plant foods as well as unimportant ${ }^{(36)}$ and small ${ }^{(37,38)}$ animal foods into 'gathering'. They also report the contribution of gathering as a percentage of subsistence economy rather than en\%. Secondly, in contrast to common belief, hunting probably played a less dominant role from a nutritional point of view compared with gathering, and on average, it makes up $35 \%$ of the subsistence base for present-day worldwide hunter-gatherers, independent of latitude or environment ${ }^{(27,37)}$. For example, hunting by some surviving hunter-gatherers is still not very successful: the probability for a kill in !Kung bushmen is only $23 \%{ }^{(37)}$, and the subsistence of Hadzabe, as described by Woodburn ${ }^{(39)}$, consists of $80 \%$ plant foods. In the Paleolithic, however, hunting might have been more productive, due to both higher animal biomass and hunter-gatherers not being displaced to marginal environments, unattractive for crop cultivation or cattle. Consequently, we chose the employed ratios within the range of the most commonly observed hunter-gatherer subsistence ratios $^{(26,27)}$.

The justification for the employed energy densities is obtained from the common misconception that members of present-day affluent societies are taller than our ancestors. The average height of Paleolithic human subjects would have placed them within the tallest $15 \%$ of our population ${ }^{(40)}$. Our former nomadic lifestyle as a hunter-gatherer was characterised by vigorous physical activity and lean body mass in contrast to the present-day sedentary lifestyle and worldwide increasing BMI. The anatomical features and physical activity of pre-agricultural humans probably demanded a greater energy intake than necessary for current Western populations. The total energy expenditure was estimated to be $10000 \mathrm{~kJ} / \mathrm{d}^{(41)}$ for Homo habilis, and $8961 \mathrm{~kJ} / \mathrm{d}$ for !Kung bushmen ${ }^{(37)}$, but was probably somewhat higher for early Homo sapiens ${ }^{(42)}$. Energy intakes should be in concordance with the physical activity level that represents the ratio between the variable total energy expenditure and the constant RMR. A typical physical activity level in the Paleolithic would be 1.74 , compared with 1.4 for a typical sedentary American and 1.75 as recommended by the $\mathrm{WHO}^{(43)}$. The daily energy expenditure, as physical activity, in the Paleolithic, however, was estimated to be $5193 \mathrm{~kJ}$, with a total energy intake of $12144 \mathrm{~kJ}$, but sedentary humans consume $8500 \mathrm{~kJ} / \mathrm{d}$, while they spend only $2324 \mathrm{~kJ} / \mathrm{d}$ on physical activity. Adjustment of the energy intake to the current physical activity level would, however, inherently imply lower nutrient intakes (i.e. LCP and micronutrients), compared with the intakes by our Paleolithic ancestors. To preclude underestimation of Paleolithic nutrient intakes, we therefore employed the daily intake of $12500 \mathrm{~kJ} / \mathrm{d}$. 
Table 1. Mean energy, fat contents and fatty acid compositions of the edible parts of foods available to our Paleolithic ancestors

\begin{tabular}{|c|c|c|c|c|c|c|c|c|c|c|}
\hline Food & $\begin{array}{l}\text { Origin of } \\
\text { the data }\end{array}$ & $\begin{array}{l}\text { Species/ } \\
\text { specimen }\end{array}$ & $\begin{array}{c}\text { Energy } \\
(\mathrm{kJ} / 100 \mathrm{~g})\end{array}$ & $\begin{array}{c}\text { Fat } \\
(\mathrm{g} / 100 \mathrm{~g})\end{array}$ & $\begin{array}{c}\text { ALA } \\
(18: 3 n-3 ; \\
\mathrm{g} / 100 \mathrm{~g})\end{array}$ & $\begin{array}{c}\text { EPA } \\
(20: 5 n-3 ; \\
\mathrm{g} / 100 \mathrm{~g})\end{array}$ & $\begin{array}{c}\text { DPA } \\
22: 5 n-3 ; \\
\mathrm{g} / 100 \mathrm{~g})\end{array}$ & $\begin{array}{c}\text { DHA } \\
(22: 6 n-3 ; \\
\text { g/100 g) }\end{array}$ & $\begin{array}{c}n-3 \\
(\mathrm{~g} / 100 \mathrm{~g})\end{array}$ & $\begin{array}{l}\text { LCP } n-3 \\
(\mathrm{~g} / 100 \mathrm{~g})\end{array}$ \\
\hline Plants & World & $49 / 49$ & 586 & 3.9 & $26 \cdot 14$ & 0.61 & 0.15 & 0.32 & $34 \cdot 10$ & 0.94 \\
\hline Fish & Africa & $68 / 68$ & 469 & 3.5 & 1.06 & $5 \cdot 18$ & 3.76 & 17.40 & $28 \cdot 36$ & $27 \cdot 12$ \\
\hline Muscle & Africa & $11 / 51$ & 452 & 2.9 & $4 \cdot 24$ & 1.34 & 2.92 & 0.37 & 8.87 & 4.64 \\
\hline Brain & World & $7 / 50$ & 528 & 9.1 & 0.20 & 0.04 & 0.63 & $9 \cdot 26$ & $10 \cdot 13$ & 9.93 \\
\hline Liver & World & $48 / 54$ & 632 & 6.7 & 4.32 & 0.99 & $2 \cdot 81$ & 1.93 & $10 \cdot 30$ & $5 \cdot 80$ \\
\hline Bone marrow & World & $11 / 73$ & 2043 & 51.0 & 1.47 & 0.08 & 0.06 & 0.07 & 1.64 & 0.21 \\
\hline Adipose tissue & World & $13 / 68$ & 3120 & 84.2 & 3.56 & 0.01 & 0.07 & 0.04 & 2.53 & 0.09 \\
\hline Food & $\begin{array}{c}\text { LA } \\
(18: 2 n-6 \\
g / 100 \mathrm{~g})\end{array}$ & $\begin{array}{c}\text { AA } \\
(20: 4 n-6 ; \\
\mathrm{g} / 100 \mathrm{~g})\end{array}$ & $\begin{array}{c}n-6 \\
(\mathrm{~g} / 100 \mathrm{~g})\end{array}$ & $\begin{array}{l}\text { LCP } n-6 \\
(\mathrm{~g} / 100 \mathrm{~g})\end{array}$ & $\begin{array}{c}\text { LCP } \\
(\mathrm{g} / 100 \mathrm{~g})\end{array}$ & $\begin{array}{c}\text { SFA } \\
(\mathrm{g} / 100 \mathrm{~g})\end{array}$ & $\begin{array}{c}\text { MUFA } \\
(\mathrm{g} / 100 \mathrm{~g})\end{array}$ & $\begin{array}{c}\text { PUFA } \\
(\mathrm{g} / 100 \mathrm{~g})\end{array}$ & $\begin{array}{c}\mathrm{LA} / \mathrm{AA} \\
(\mathrm{g} / \mathrm{g})\end{array}$ & $\begin{array}{c}(E P A+D H A) / \\
A A(g / g)\end{array}$ \\
\hline Plants & 13.98 & 0.64 & $15 \cdot 84$ & 0.87 & 1.81 & 29.25 & 12.51 & $42 \cdot 29$ & 0.54 & 1.45 \\
\hline Fish & $2 \cdot 19$ & 8.45 & 16.03 & 13.80 & 40.92 & 37.01 & 18.59 & 44.40 & 2.07 & $2 \cdot 67$ \\
\hline Muscle & 20.59 & $6 \cdot 40$ & 28.65 & $7 \cdot 17$ & 11.24 & 39.16 & 21.58 & $36 \cdot 34$ & 4.85 & 0.27 \\
\hline Brain & 0.69 & 5.74 & $12 \cdot 01$ & $11 \cdot 32$ & $21 \cdot 25$ & 31.78 & 27.63 & $22 \cdot 14$ & 3.51 & 1.62 \\
\hline Liver & 14.87 & 9.40 & $26 \cdot 21$ & $10 \cdot 16$ & $15 \cdot 96$ & $35 \cdot 29$ & $26 \cdot 01$ & 35.94 & 3.44 & 0.31 \\
\hline Bone marrow & 3.18 & 0.16 & 3.60 & 0.23 & 0.44 & $23 \cdot 23$ & 64.51 & 6.04 & $2 \cdot 16$ & 0.94 \\
\hline Adipose tissue & $5 \cdot 41$ & 0.21 & $5 \cdot 86$ & 0.22 & 0.49 & $51 \cdot 15$ & $35 \cdot 17$ & 9.53 & 1.52 & 0.25 \\
\hline
\end{tabular}

Origin, origin of the investigated foods; species/specimen, ratio of investigated numbers of species and specimen; ALA, $\alpha$-linolenic acid; DPA, docosapentaenoic acid; LCP, long-chain PUFA; LA, linoleic acid; AA, arachidonic acid; SFA, sum of all SFA: MUFA, sum of all MUFA. 
We employed selective hunter-gathering/scavenging (i.e. including brain and bone marrow) in Models 1 and 3, but non-selective hunter-gathering/scavenging (i.e. including all edible organs) in Models 2 and 4. Selective organ consumption would increase both the fat (hence the energy) and the LCP contents of the meat (Tables 1 and 2). To elucidate this net effect of selective organ consumption, we modelled the influence of increased organ tissue consumption ${ }^{(44-47)}$ on the macronutrient and fatty acid intakes. The exclusion of liver and adipose tissue in Models 1 and 3 is obtained from the observation that scavenged leftovers from carnivore kills seldom contain energy-dense organs such as the liver and adipose tissue ${ }^{(45)}$. Liver and adipose tissue are the first to be consumed by the obligate carnivore, while the head and bones are the most likely leftovers because of their inaccessibility ${ }^{(44)}$. Although it has been suggested that, apart from the remaining muscle meat ${ }^{(44-46,48)}$, tool-using huntergatherer scavengers ${ }^{(48)}$ could have had selective access to brain and marrow ${ }^{(44-47)}$ for the main period of human evolution, it seems unlikely that brain or marrow would have been as easily accessible for consumption as aquatic LCPrich animal foods, especially for women and children. Although both marrow and brain are sizeable, energy-dense organs $^{(45-47)}$ (supplementary Table S2, available online only at http://journals.cambridge.org), a substantial contribution from marrow and brain to any regular diet seems unlikely with regard to their sizes and perishability. The high marrow/brain $(80 / 20$ en\%/en\%) contribution to the total meat en\% was therefore included to investigate one of the possible ranges of nutrient intakes, rather than the most realistic or average. From approximately the middle Stone Age on, after humans became top predators, not only brain and marrow but also liver and adipose tissue would have become more frequently accessible (i.e. Model 2). The selective consumption of energy-dense organs (fat) is consistent with the optimal foraging theory, and their preferential consumption was indeed observed in present day hunter-gatherers (RS Kuipers and MF Luxwolda, personal observations). In support of optimal foraging, it was recently shown that after fasting, the human brain responded more actively to pictures of high-energy foods compared with low-energy foods ${ }^{(30)}$.

\section{Plant composition}

The macronutrient composition and energy value of plant foods (Table 2) were derived from Eaton et al. ${ }^{(26)}$ (fat $19 \mathrm{en} \%$; protein $13 \mathrm{en} \%$ and carbohydrate $68 \mathrm{en} \%)$ and Cordain et al. ${ }^{(27)}$ (fat $24 \mathrm{en} \%$; protein $14 \mathrm{en} \%$ and carbohydrate $62 \mathrm{en} \%$ ). They assumed a range from $469 \mathrm{~kJ} / 100 \mathrm{~g}$ at $2.1 \mathrm{~g} \%$ plant fat $^{(26)}$ to $699 \mathrm{~kJ} / 100 \mathrm{~g}$ at $5 \mathrm{~g} \%$ plant fat ${ }^{(27,49)}$. For Model 1 , we adopted a $2.5 \mathrm{~g} \%$ plant fat figure, while for Models $2-4$, we varied the fat contents of plant from 2.5 to $5 \mathrm{~g} \%$. Cordain et al. ${ }^{(27)}$ used a mean plant fat content of $5 \mathrm{~g} \%$, as derived from 829 wild plant foods consumed by Australian Aboriginals ${ }^{(49)}$. The fatty acid compositions of plant foods (Table 1) were derived from Guil et al. ${ }^{(50)}$, as also used by Eaton $e t$ al. ${ }^{(26)}$, with additional data for African vegetables such as terrestrial leaves, seeds, roots, tubers, nuts and fruits ${ }^{(51-55)}$. Edible seaweed, sea grasses and algae ${ }^{(56-59)}$, like insects ${ }^{(60,61)}$, were not included, but they are shown for comparison in supplementary Table S1 (available online only at http://journals.cambridge.org).

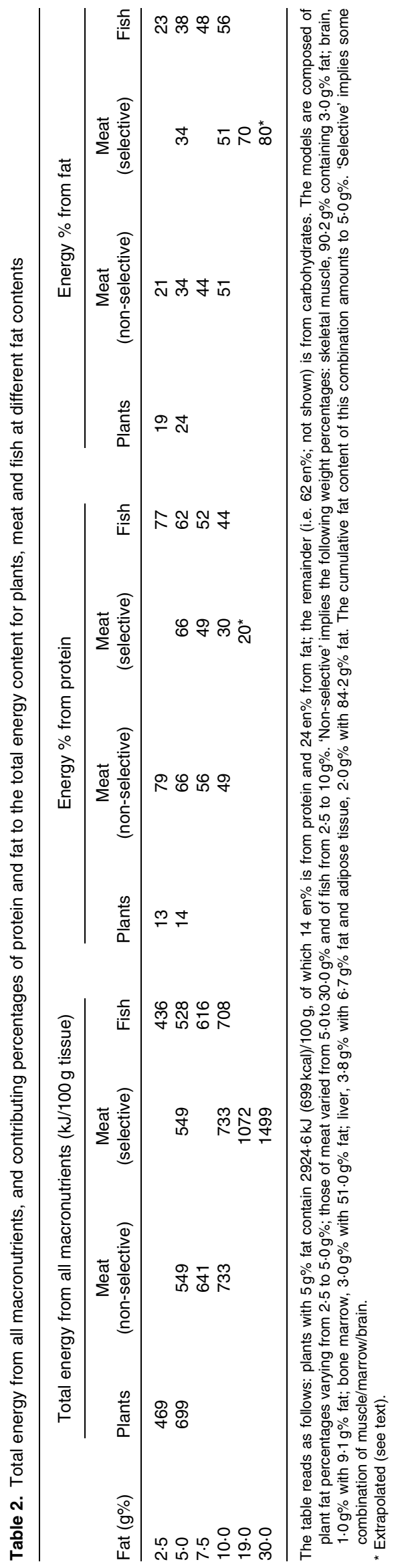


Marine plants, terrestrial plants and insects have comparable fatty acid contents, except for the somewhat higher LCP and lower precursor contents in marine plants.

Justification for using the range of plant fat percentages in our models may be obtained from examples of currently consumed plant foods in East Africa. Tubers consumed by the Hadzabe in Tanzania contain up to $5 \mathrm{~g} \%$ fat $^{(54)}$. Although indigenous to North America, Congolese tribes consume avocados that contain $19 \mathrm{~g} \%$ fat $^{(53)}$. Coconuts contain $46 \mathrm{~g} \%$ fat and could have been available to our ancestors ${ }^{(35)}$, while palm nuts and peanuts contain 46 and $49 \mathrm{~g} \%$ fat, respectively ${ }^{(53)}$. Nigerian wild plant seeds contains up to $59 \mathrm{~g} \%$ fat $^{(51)}$, nuts consumed by Australian Aborigines contain on average $29 \mathrm{~g} \%$ fat $^{(49)}$ and the !Kung Bushmen consumed fat-rich mongongo nuts $\left(57 \mathrm{~g} \%\right.$ fat) as staple food when available ${ }^{(55)}$. The preference of nuts or fatty fruits above low-fat leaves is consistent with optimal foraging ${ }^{(29-31)}$.

\section{Meat composition}

Non-selective meat consumption. Animal foods were subdivided into muscle, brain, bone marrow, liver and adipose tissue/separable fat. About $50 \%$ of the total body weight of game animals is edible ${ }^{(62)}$. For the calculation of the energy density and the energy contributions of protein and fat from an average edible portion of non-selectively consumed meat, we assumed the following weight distribution and fat contents: skeletal muscle $90.2 \mathrm{~g} \%$ containing $2.9 \mathrm{~g} \%$ fat; brain $1.0 \mathrm{~g} \%$ with $9.1 \mathrm{~g} \%$ fat; liver $3.8 \mathrm{~g} \%$ with $6.7 \mathrm{~g} \%$ fat; bone marrow $3.0 \mathrm{~g} \%$ with $51.0 \mathrm{~g} \%$ fat and adipose tissue $2.0 \mathrm{~g} \%$ with $84.2 \mathrm{~g} \%$ fat $^{(26,45,46,53,63-70)}$. The cumulative fat percentage of a non-selectively consumed portion of meat amounts to $4.89 \mathrm{~g} / 100 \mathrm{~g}^{(26)}$, which was rounded to $5.0 \mathrm{~g} \%$ fat for practical purposes, with a corresponding energy density of $549 \mathrm{~kJ} / 100 \mathrm{~g}$ (see Table 2). For the various fat contents of non-selectively consumed meat (i.e. $2 \cdot 5-10 \mathrm{~g} \%$ ), we calculated the energy densities and the energy contributions of protein and fat. For meat, the relationships between energy density and fat content, and between energy from protein and fat content, are linear, as noted previously by Cordain et al. ${ }^{(27)}$. The employed relationships are presented in equations (1) and (2) as follows ${ }^{(27)}$ :

Energy density of meat (in $\mathrm{kJ} / \mathrm{g}$ ) $=3.616+0.371 \times$ body fat $(\%$ by weight $)$,

Energy contribution of protein (in $\mathrm{kJ} / \mathrm{g}$ )

$$
\begin{aligned}
= & 96.79-(7.92 \times \text { body fat }(\% \text { by weight }))+(0.403 \\
& \left.\times(\text { body fat }(\% \text { by weight }))^{2}\right)-(0.0090 \\
& \left.\times(\text { body fat }(\% \text { by weight }))^{3}\right) .
\end{aligned}
$$

The fat contents of meat (in en\%) were calculated by considering $100 \mathrm{en} \%$ minus the protein en $\%$. The final outcomes are presented in Table 2.

Selective meat consumption. The energy density and the contributions of protein and fat from an average portion of selectively consumed meat were calculated at three different fat contents (i.e. $10.0 ; 19.0$ and $30.0 \mathrm{~g} \%$ ). These fat percentages were derived from three different combinations of muscle, marrow and brain, i.e. 50/40/10, 20/64/16 and $0 / 80 / 20$ en $\% / e n \% / e n \%$, respectively. Justifications for these combinations are obtained from the observation (see Results section) that protein intakes exceed the stated protein constraint (see below) from about 50 en $\%$ muscle consumption. Since brain and bone marrow have similar total weights (supplementary Table S2, available online only at http://journals. cambridge.org) ${ }^{(45-47)}$, but bone marrow has about four times higher energy density (Table 1), we kept the bone marrow/ brain constant at a ratio of 4 en\%/en\%.

The calculations of the fat content ( $\mathrm{g} \%)$, energy from all macronutrients $(\mathrm{kJ} / 100 \mathrm{~g})$, and protein and fat contributions (in en\%) may be illustrated as follows. A ratio of 20/64/ 16 en $\% /$ en $\% / e n \%$ from muscle, bone marrow and brain, respectively, implies that for each $4188 \mathrm{~kJ}$ selectively consumed meat of this composition 838, 2680 and $670 \mathrm{~kJ}$ are derived from muscle, bone marrow and brain, respectively. Using the energy densities of these organs as given in Table 1 , the energy quantities translate into $838 / 452=185 \mathrm{~g}$ muscle, $2680 / 2043=131 \mathrm{~g}$ bone marrow and 670/528 $=127 \mathrm{~g}$ brain. These figures add to a total of $443 \mathrm{~g}$ selectively consumed meat, of which $41.7 \mathrm{~g} \%$ is derived from muscle, $29.6 \mathrm{~g} \%$ is derived from marrow and $28.7 \mathrm{~g} \%$ is derived from brain. The total fat content of this $443 \mathrm{~g}$ portion was calculated by using the fat contents of the individual organs as given in Table 1, yielding $19 \mathrm{~g} \%$ fat (see Table 2). The energy contribution from all macronutrients and the contribution from protein were subsequently calculated by using equations (1) and (2), respectively (see earlier), yielding $1072 \mathrm{~kJ} / 100 \mathrm{~g}$ selectively consumed meat and $30 \mathrm{en} \%$ from protein. The fat content (in en $\%$ ) was calculated by considering 100 en $\%$ minus the protein en $\%$. The fat content $(\mathrm{g} \%)$, energy from all macronutrients $(\mathrm{kJ} / 100 \mathrm{~g})$, and protein and fat contributions (in en $\%$ ) for the 50/40/10 and 0/80/20 en $\% /$ en $\% / e n \%$ compositions were calculated in a similar manner. These calculations needed extrapolation for the 0/80/20 composition, since the original data of Cordain's ${ }^{(27)}$ equation (2) did not consider fat percentages above $25 \mathrm{~g} \%$. The final outcomes of the calculations for each of the organ combinations for selectively consumed meat are presented in Table 2 .

Justification for the use of variable fat percentages in our models is obtained from the available data from East African animal and hunter-gatherer studies. The nutrient composition of the various tissue compartments in animals is variable. For instance, the fat content of skeletal muscle from game animals is much lower than that of livestock ${ }^{(46,63,71)}$, and ranged from $2.0 \mathrm{~g} \%$ in the Ugandan Eland ${ }^{(67)}$ to $4.6 \mathrm{~g} \%$ in monkey bush meat from Zaire ${ }^{(53)}$ in our database, but it can be as high as $25 \mathrm{~g} \%$ in domestic cattle ${ }^{(63)}$. The fat content of bone marrow strongly depends on season and the animal's age and physical condition $^{(45,46)}$. Also the size of the adipose tissue mass of game animals is dependent on season, condition and age ${ }^{(45-47)}$. In contrast to the afore-mentioned organs, the fat contents of liver and brain are rather constant ${ }^{(46)}$. In view of this variance and the optimal foraging theory ${ }^{(29-31)}$, we varied the average fat content of the consumed whole carcass edible meat from 5.0 to $10.0 \mathrm{en} \%$, and to a maximum of 30.0 en\% for (very) selective organ consumption in Models 1 and 3 to calculate the energy value and the macronutrient and fatty acid compositions of the possible diets. It is important to realise that the consumption of 'meat' containing $30 \mathrm{~g} \%$ 
fat does not refer to consumption of lean muscle meat only, since the maximum lean meat fat $\%$ of some East African mammal species was $13.0 \mathrm{~g} \%$ in a female hippopotamus in Ledger's classical study ${ }^{(62)}$. We rather point at the selective consumption of fatty organs as the brain and bone marrow or liver and adipose tissue. Secondly, selective hunting would be part of optimal foraging strategies ${ }^{(29-31)}$, meaning that hunter-gatherers would spend more effort in hunting fat animals than in hunting lean animals. With reference to the employment of a wide range of dietary fat, we emphasise that the present study is rather designed to show the range of possible dietary intakes from a constantly changing environment in the past than to point at one specific dietary composition.

\section{Fish composition}

At various body fat contents of fish (i.e. $2.5 ; 5.0 ; 7.5$ and $10.0 \mathrm{~g} \%$ ), we calculated the energy density and the contributions of protein and fat (in en $\%$ ). From the USDA food database ${ }^{(33)}$, we found that the energy densities for fish correlate excellently with the corresponding body fat contents (Fig. 1). Using the linear relationship energy density $(\mathrm{kJ} / \mathrm{g})=0.3663 \times$ body fat $($ in $\mathrm{g} \%)+3.4246\left(R^{2} 0.9425\right)$, we subsequently calculated the energy densities at the various body fat contents of fish. The corresponding energy contributions of protein were calculated from the following equation $^{(27)}$ :

$$
\begin{array}{r}
\text { Protein }(\text { en\%) }=97 \cdot 67-(9.45 \times \text { body fat }(\mathrm{g} \%))+(0 \cdot 535 \\
\left.\quad \times(\text { body fat }(\mathrm{g} \%))^{2}\right)-\left(0.0127 \times(\text { body fat }(\mathrm{g} \%))^{3}\right) .
\end{array}
$$

The fat contents of fish (in en\%) were calculated by considering 100 en $\%$ minus the protein en $\%$. The final outcomes are presented in Table 2.

Justification for the employed fat percentages from fish may be obtained from the following data. The fat content of most pelagic fish is about $2.5 \mathrm{~g} \%$, but African catfish have fat contents above $10 \mathrm{~g} \%^{(72)}$. In most studies, the fat content is derived from the analyses of the fillet, while Pauletto et $a l^{(72)}$ specifically examined a portion including the fat-rich skin $\left(37-44 \mathrm{~g} \%\right.$ of total fat ${ }^{(73)}$. In addition to

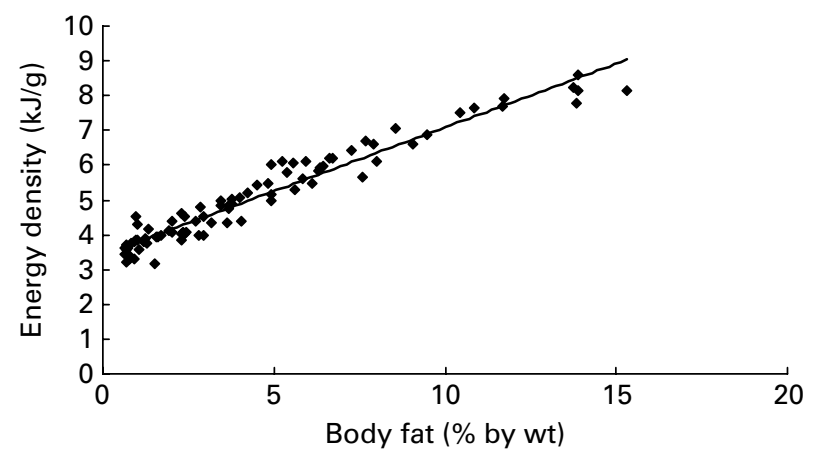

Fig. 1. Relation between body fat (in $\mathrm{g} \%$ ) and energy density (in $\mathrm{kJ} / \mathrm{g}$ ) for fish. All the data on freshwater fish are derived from the USDA Internet database ( $n$ 87), accessed on 15 August $2008^{(33)} . y=0.3663 x+3.4246$; $R^{2} 0.9425$ the consumption of skin, the first part of a fish to be consumed by Africans is the head, which contains $10-17 \mathrm{~g} \%$ of total fat $^{(73)}$. Another $3 \cdot 5-6 \mathrm{~g} \%$ of fat may come from the consumption of the backbone ${ }^{(73)}$. Although large fish were reportedly caught with bare hands back to 2 million years ago ${ }^{(12)}$, especially in smaller fish, the skin would have been a substantial part of the total edible portion. For instance, we estimate that $2-20 \mathrm{~g} \%$ fat would be derived from the whole consumption of a $10 \mathrm{~cm}$ fish with a diameter of $3 \mathrm{~cm}$ and a $2 \mathrm{~mm}$ skin. Taking these assumptions into account for the approximation of the average fat content of the fish consumed by early humans, we varied the average fat content of fish in our models from 2.5 to $10.0 \mathrm{~g} \%$. Since 'you are what you eat' also applies to fish, we only used fatty acid data on East African fish species. The differential fatty acid status of worldwide and East African fish species ${ }^{(9,34,35,72,73)}$ are presented in supplementary Table S1 (available online only at http://journals. cambridge.org). Data for the fatty acid composition of some other typical marine animals, such as crustaceans, cephalopods and certain marine reptiles, birds, mammals, including their eggs, livers and adipose tissue are presented in supplementary Table S1 (available online only at http://journals.cambridge. org), but they are not included in the models. The fatty acid compositions are quite similar to that of the employed African fish species.

\section{Calculation example}

The example assumes a $12500 \mathrm{~kJ} / \mathrm{d}$ diet that is composed of $70 \mathrm{en} \%$ plant (containing $2.5 \mathrm{~g} \%$ fat) and $30 \mathrm{en} \%$ animal food. The latter is composed of $15 \mathrm{en} \%$ fish with $2.5 \mathrm{~g} \%$ fat and $15 \mathrm{en} \%$ meat. The meat was either non-selectively consumed with $5 \mathrm{~g} \%$ fat or selectively consumed with $19 \mathrm{~g} \%$ fat.

Macronutrient composition. The protein contribution from plants in this example would be $12500 \mathrm{~kJ} / \mathrm{d} \times 70 \mathrm{en} \% \times 13 \mathrm{en} \%$ (Table 2$)=1143 \mathrm{~kJ} / \mathrm{d}$. Similarly, the protein contribution from meat would be $12500 \times 15 \% \times 66 \%($ Table 2$)=1244 \mathrm{~kJ} / \mathrm{d}$, while the protein contribution from fish is $12500 \times$ $15 \% \times 77 \%($ Table 2$)=1453 \mathrm{~kJ} / \mathrm{d}$. Taken together, the total protein intake from this $12500 \mathrm{~kJ} / \mathrm{d}$ diet would be $1143+1244+1453=3840 \mathrm{~kJ} / \mathrm{d}$, which equals $30.6 \mathrm{en} \%$ of total energy intake. The corresponding fat and carbohydrate intakes were $2747 \mathrm{~kJ} / \mathrm{d}(21.9 \mathrm{en} \%)$ and $5980 \mathrm{~kJ} / \mathrm{d}(47.5 \mathrm{en} \%)$, respectively.

The macronutrient contribution for $19 \%$ fat in selectively consumed meat is calculated in a similar manner. The protein contribution from plants would again be $1143 \mathrm{~kJ} / \mathrm{d}$ (see earlier). The protein contribution from meat would be $12500 \times 15 \% \times 30 \%($ Table 2$)=565 \mathrm{~kJ} / \mathrm{d}$, while the protein contribution from fish would again be $1453 \mathrm{~kJ} / \mathrm{d}$ (see earlier). Taken together, the total protein intake from this $12500 \mathrm{~kJ} / \mathrm{d}$ diet would be $1143+565+1453=3161 \mathrm{~kJ} / \mathrm{d}$, which equals 25.2 en $\%$ of total energy intake. The corresponding fat and carbohydrate intakes were $3425 \mathrm{~kJ} / \mathrm{d}(27 \cdot 3 \mathrm{en} \%)$ and $5980 \mathrm{~kJ} / \mathrm{d}$ (47.5 en $\%)$, respectively.

Fatty acid composition: arachidonic acid as an example. Table 3 shows the outcome of the AA content per $100 \mathrm{~g}$ of consumed meat, as calculated by assuming non-selective and selective meat consumption, respectively. Data for all other fatty acids given in Table 1 were also calculated 
Table 3. Arachidonic acid (AA) content of $100 \mathrm{~g}$ consumed meat assuming non-selective (whole carcass) consumption or selective organ consumption

\begin{tabular}{|c|c|c|c|c|}
\hline Tissue & $\operatorname{Organ}^{*}(\mathrm{~g})$ & Fat† ( $g \%)$ & $A A \ddagger(g \%)$ & $\mathrm{AA} \S(\mathrm{mg})$ \\
\hline \multicolumn{5}{|c|}{ Non-selective consumption|| } \\
\hline Muscle & $90 \cdot 2$ & 2.9 & $6 \cdot 40$ & 167 \\
\hline Brain & 1.0 & $9 \cdot 1$ & $5 \cdot 74$ & 5 \\
\hline Liver & $3 \cdot 8$ & 6.7 & $9 \cdot 40$ & 24 \\
\hline Bone marrow & 3.0 & $51 \cdot 0$ & 0.16 & 2 \\
\hline Adipose tissue & $2 \cdot 0$ & $84 \cdot 2$ & 0.21 & 3 \\
\hline Total & $100 \cdot 0$ & & & 203 \\
\hline \multicolumn{5}{|c|}{ Selective consumption } \\
\hline Muscle & 41.7 & 2.9 & $6 \cdot 40$ & 80 \\
\hline Brain & 28.7 & $9 \cdot 1$ & $5 \cdot 74$ & 150 \\
\hline Liver & 0.0 & 6.7 & 9.40 & 0 \\
\hline Bone marrow & 29.6 & $51 \cdot 0$ & 0.16 & 24 \\
\hline Adipose tissue & 0.0 & 84.2 & 0.21 & 0 \\
\hline Total & $100 \cdot 0$ & & & 254 \\
\hline \multicolumn{5}{|c|}{ 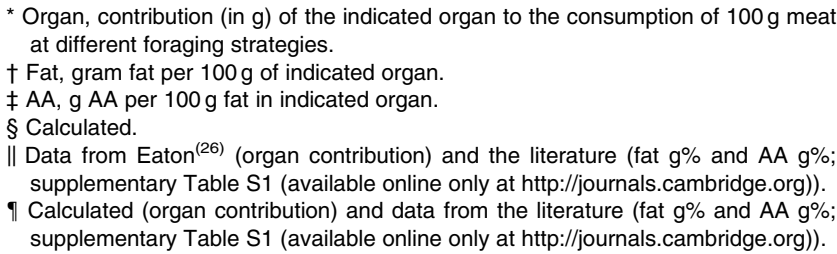 } \\
\hline
\end{tabular}

(not shown). The employed AA data in plants and fish are presented in Table 1.

A $12500 \mathrm{~kJ} / \mathrm{d}$ diet with $70 \mathrm{en} \%$ from plants corresponds with $8794 \mathrm{~kJ} / \mathrm{d}$ from plants. The energy density from plants at $2.5 \mathrm{~g} \%$ fat is $469 \mathrm{~kJ} / 100 \mathrm{~g}$ (Table 2), which translates the $8794 \mathrm{~kJ} / \mathrm{d}$ into an intake of $8794 / 4.69=1875 \mathrm{~g}$ plants $/ \mathrm{d}$. The plants were assumed to contain $2.5 \mathrm{~g} \%$ fat with an AA content of $0.64 \mathrm{~g} / 100 \mathrm{~g}$ fat (Table 1 ), which implies a total daily AA intake of $1875 \times 2.5 / 100 \times 0.64 / 100=0.30 \mathrm{~g}$ from plants. Similarly, $15 \mathrm{en} \%$ from fish with $2.5 \mathrm{~g} \%$ fat translates into $12500 \times 15 / 100 \times 100 / 436 \times 2.5 / 100 \times 8.45 / 100=0.91 \mathrm{~g}$ AA/d (Table 2). The daily amount of meat from non-selective consumption at $15 \mathrm{en} \%$ would be $12500 \times 15 / 100 \times 100 /$ $549=344 \mathrm{~g}$ meat (Table 2). With an average content of $203 \mathrm{mg}$ AA per $100 \mathrm{~g}$ non-selectively consumed meat (Table 3), this figure adds up to $344 \times 0.203 / 100=0.70 \mathrm{~g}$ AA/d. Assuming selective consumption of meat, the daily intake of AA would become $12500 \times 15 / 100 \times 100 / 1072$ (Table 2) $\times 0.254 / 100$ (Table 3$)=0.45 \mathrm{~g}$. Taken together, the intake of AA in this example from plants, fish and non-selectively consumed meat would be $0.30+0.91+0.70=1.91 \mathrm{~g}$, while for selective meat consumption, the intake would be $0.30+0.92+0.45=1.67 \mathrm{~g}$ $\mathrm{AA} / \mathrm{d}$. Additional calculation of the daily intakes of all other fatty acids and subsequent normalisation to g/100 $\mathrm{g}$ fatty acids gave rise to the dietary fatty acid composition (detailed data not shown).

\section{Constraints}

Since not all dietary combinations are compatible with good health, we introduced two pathophysiological constraints. First, the contribution of protein is not allowed to exceed 35 en $\%$, since this may cause 'rabbit starvation', probably by exceeding the maximum capacity of the liver to convert the excess nitrogen into urea ${ }^{(74)}$. Some studies even suggest that in adult male hunter-gatherers the protein intake may be closer to $40-50$ en ${ }^{(75)}$. The constraint to restrict the average protein intake at 35 en $\%$ seems, however, justified by the hunter-gatherer observations ${ }^{(76)}$. Secondly, LA intakes were to be above 1.0 en $\%$ to prevent LA deficiency, especially in children. This constraint is derived from the original data of Burr \& Burr ${ }^{(77)}$, as revisited by Cuthbertson ${ }^{(78)}$, who even stated that 'the minimum requirements for LA are in fact less than $0.5 \%$ of calories'; and set at a minimum requirement of at least $1.0 \%$ of energy as LA to prevent biochemical LA deficiency. In animals, the minimum requirement for LA could also be met by $\gamma$-LA and $\mathrm{AA}^{(79)}$, which would actually imply that the currently employed constraint for LA would be superfluous for any diet containing substantial amounts of LCP $n-6$ (see also Discussion). In addition to these two constraints, we tested whether the reconstructed diets provide the daily intake of $450-500 \mathrm{mg} \mathrm{EPA}+\mathrm{DHA} / \mathrm{d}$ to lower CHD risk, as recommended by the UK Scientific Advisory Committee on Nutrition, the WHO and International Society for the Study of Fatty Acids and Lipids ${ }^{(80)}$.

\section{Results}

\section{Means and ranges of the models}

The extremes for Models 1, 2 and 3, i.e. the 70/30 and 30/ 70 en $\% /$ en $\%$ plant/animal subsistence ratios, are depicted in Figs. 2 and 3, respectively. For Model 1, a total of 105 different diets were evaluated. Of these, seventy-one $(68 \%)$ diets met the protein constraint, and thereafter all the models met the LA constraint and the EPA + DHA recommendation. For Model 2, we evaluated a total of 1320 different diets, of which $674(51 \%)$ diets met the protein constraint, and thereafter all the models met the LA constraint and the $\mathrm{EPA}+\mathrm{DHA}$ recommendation. Model 3 considered a total of 165 different diets, of which $115(70 \%)$ diets met the protein constraint, and thereafter all the models met the LA constraint and the EPA + DHA recommendation. Model 4 is an extreme of Model 2 (or 3), and describes plant and fish intakes only. Since the model is two-dimensional, instead of multidimensional, it is not depicted separately. The model evaluated forty options, of which twenty-two (55\%) options met the protein constraint, and thereafter all the models met the LA constraint and the EPA + DHA recommendation.

Fig. 2 represents data for Model 1 at a $70 / 30$ en\%/en\% plant/animal subsistence ratio, assuming the following fat contents: plants $2.1 \mathrm{~g} \%$, muscle $3.0 \mathrm{~g} \%$, bone marrow $51 \mathrm{~g} \%$ and brain $9.1 \mathrm{~g} \%$. The contribution of muscle/marrow/brain to the consumed meat (in en\%) was varied from $98 / 1 / 1$ to $0 / 80 / 20$ en $\% /$ en $\% / e n \%$. The shorthand notations of these extremes (see $X$-axis labels) would be $70 / 98 / 1 / 1$ to $70 / 0 /$ $80 / 20$, in which the first figure represents the en\% from plants, and the last three figures represent the en\% contributions from muscle/marrow/brain in the remaining $30 \mathrm{en} \%$ animal food (i.e. only meat in Model 1), all at the fixed fat contents (in $\mathrm{g} / 100 \mathrm{~g}$ material). The data in this example show that replacing muscle for bone marrow and brain (i.e. $X$-axis from left to right) causes a decrease in the contributions of LA and protein (both in en\%), and increases in the ALA/LA 


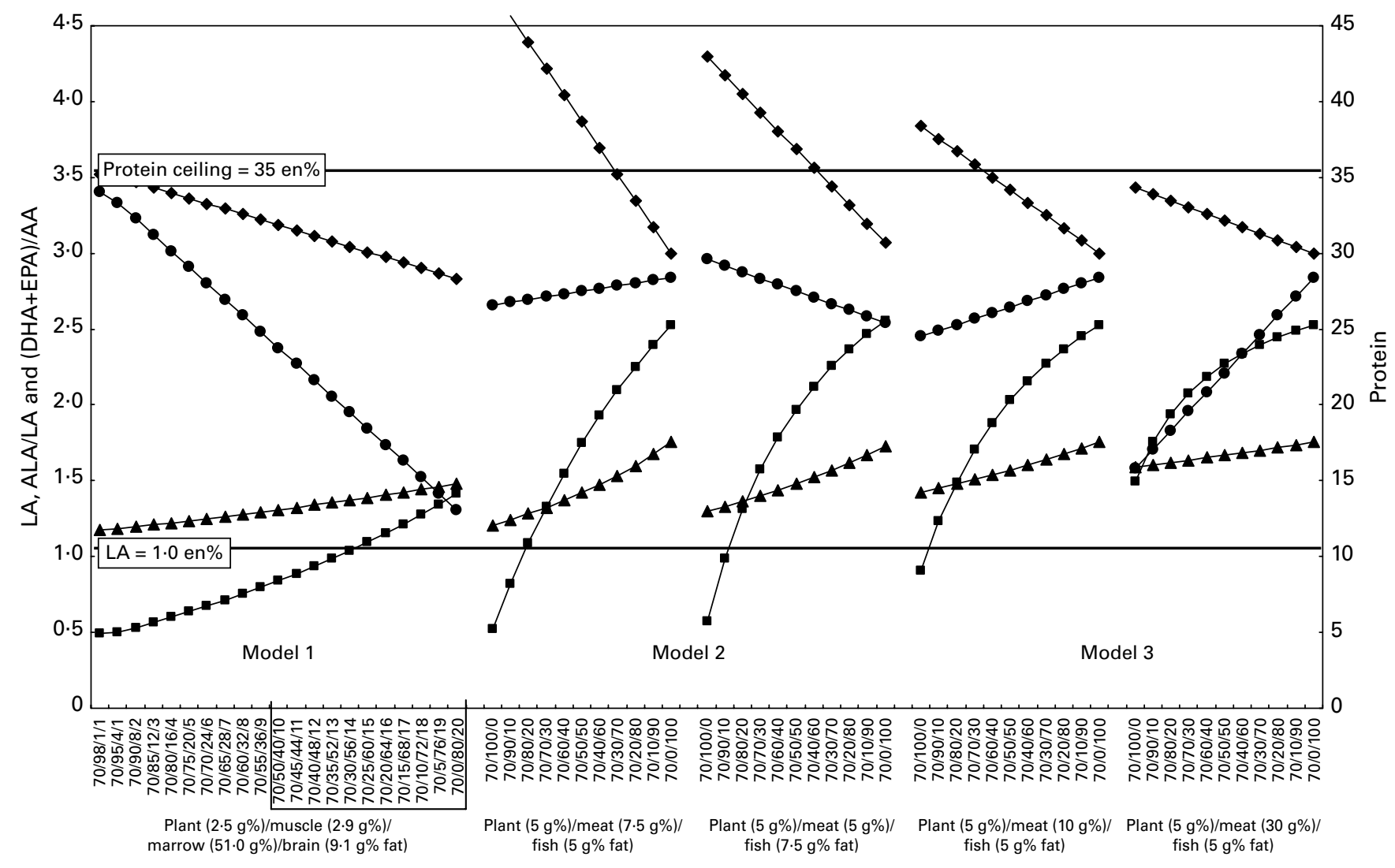

Fig. 2. The courses of the protein (total energy from protein, - - -, en\%) and linoleic acid (LA) intakes (- - in en\%) and the $\alpha$-linolenic acid (ALA)/LA (- - -) and (EPA + DHA)/arachidonic acid (AA) ratios (- - , in g/g) with changing composition of animal food at a $70 / 30$ en\%/en\% plant/animal subsistence ratio. Animal food was composed of organ meat (skeletal muscle, brain, bone marrow, liver and adipose tissue) and fish. Meat consumption was either selective (Models 1 and 3) or non-selective (Model 2). The shorthand notation on the $X$-axis indicates plant/muscle/marrow/brain (Model 1) and plant/meat/fish (Models 2 and 3). Note the differences of the left and right scales of the $Y$-axes. The range of dietary combinations within the box in Model 1 was used for the construction of Model 3 (see text). Horizontal lines depict the employed protein $(<35 \mathrm{en} \%)$ and LA $(>1.0 \mathrm{en} \%)$ constraints. The data for Model 1 (a selective hunter-gatherer/scavenger savannah diet) were calculated by assuming the selective consumption of plant, muscle, bone marrow and brain with the fat contents of $2.5,2.9,51.0$ and $9.1 \mathrm{~g} \%$, respectively. Their intakes were varied between 98 and $0 \mathrm{en} \%$ (skeletal muscle), 1 and $80 \mathrm{en} \%$ (bone marrow) and 1 and $20 \mathrm{en} \%$ (brain) of the total meat intake. The data for Model 2 (a non-selective hunter-gatherer/scavenger aquatic diet) were calculated by assuming non-selective consumption of edible meat with the following weight distribution and fat contents: skeletal muscle $90.2 \mathrm{~g} \%$ containing $2.9 \mathrm{~g} \%$ fat; brain $1.0 \mathrm{~g} \%$ with $9.1 \mathrm{~g} \%$ fat; bone marrow $3.0 \mathrm{~g} \%$ with $51.0 \mathrm{~g} \%$ fat; liver $3.8 \mathrm{~g} \%$ with $6.7 \mathrm{~g} \%$ fat and adipose tissue $2.0 \mathrm{~g} \%$ with $84.2 \mathrm{~g} \%$ fat ${ }^{(25,45,46,53,62-69)}$. The fat percentages were $5 \mathrm{~g} \%$ for plants, $5.0 \mathrm{~g} \%$ for fish and $7.5 \mathrm{~g} \%$ for whole carcass meat (left panel of Model 2), and $5 \mathrm{~g} \%$ for plants, $7.5 \mathrm{~g} \%$ for fish and $5.0 \mathrm{~g} \%$ for whole carcass meat (right panel of Model 2). The data for Model 3 (a selective hunter-gatherer/scavenger savannah/aquatic diet) were calculated by assuming the selective consumption of muscle, bone marrow and brain with the fat contents of $2.9,51.0$ and $9.1 \mathrm{~g} \%$, respectively. The meat and fish intakes were varied from 100 to 0 and 0 to 100 en\% of total animal consumption, respectively. The intakes from muscle, bone marrow and brain were varied (from left to right panel of Model 3) from 0 to 50 en\% (muscle), 40 to 80 en\% (bone marrow) and 10 to $20 \mathrm{en} \%$ (brain) of total meat intake. The fat contents of fish and plants were both set at $5 \mathrm{~g} \%$, while the average fat contents of the combined muscle/ marrow/brain in meat varied from 10 (left panel of Model 3) to $30 \mathrm{~g} \%$ (right panel of Model 3).

and (EPA + DHA)/AA ratios (both in g/g). All the investigated meat compositions within the depicted $70 /$ 30 en $\% / e n \%$ plant/animal example of Model 1 complied with $<35 \mathrm{en} \%$ protein, $>1.0 \mathrm{en} \%$ LA constraints and met the $>450 \mathrm{mg} \mathrm{EPA}+\mathrm{DHA}$ recommendation. Similarly, Fig. 3 shows data for Model 1 at the 30/70 en\%/en\% plant/ animal subsistence ratio. The fat contents of plant, muscle/ marrow/brain and the animal compositions were the same as described previously. The protein constraint was met from a ratio of 30/50/40/10. All the animal compositions complied with the energy constraints for LA and the $450 \mathrm{mg}$ $\mathrm{EPA}+\mathrm{DHA}$ recommendation.

For Model 2, examples are shown for $5 \mathrm{~g} \%$ fat in plants, $5.0 \mathrm{~g} \%$ fat in fish and $7.5 \mathrm{~g} \%$ fat in whole carcass meat (Model 2, Figs. 2 and 3, left panels), and for $5 \mathrm{~g} \%$ fat in plants, $7.5 \mathrm{~g} \%$ fat in fish and $5.0 \mathrm{~g} \%$ fat in whole carcass meat (Model 2, Figs. 2 and 3, right panels). The meat/fish compositions were varied from $100 / 0$ to $0 / 100$ en $\% /$ en $\%$ of total animal food. As shown in Fig. 2 in the left panel, for Model 2, the compliance with the protein and LA constraints and the EPA + DHA recommendation was reached for all dietary compositions.

Finally, for Model 3, examples are shown for the 70/ 30 en $\% /$ en $\%$ (Fig. 2) and 30/70 en\%/en\% (Fig. 3) plant/ animal subsistence ratios, but here at 50/40/10 (left panels) and $0 / 80 / 20$ (right panels) for the muscle/marrow/brain ratios. The fat contents were $5 \mathrm{~g} \%$ for plants, $10 \mathrm{~g} \%$ for meat and $5 \mathrm{~g} \%$ for fish (left panels), and $5 \mathrm{~g} \%$ for plants, $30 \mathrm{~g} \%$ for meat and $5 \mathrm{~g} \%$ for fish (right panels). Justifications for these fat percentages are obtained from the application of the protein constraints to Model 1 in Fig. 3, which fixed the muscle/marrow/brain ratios in meat between $50 / 40 / 10$ and $0 / 80 / 20$, and also consequently fixed the fat percentages. 


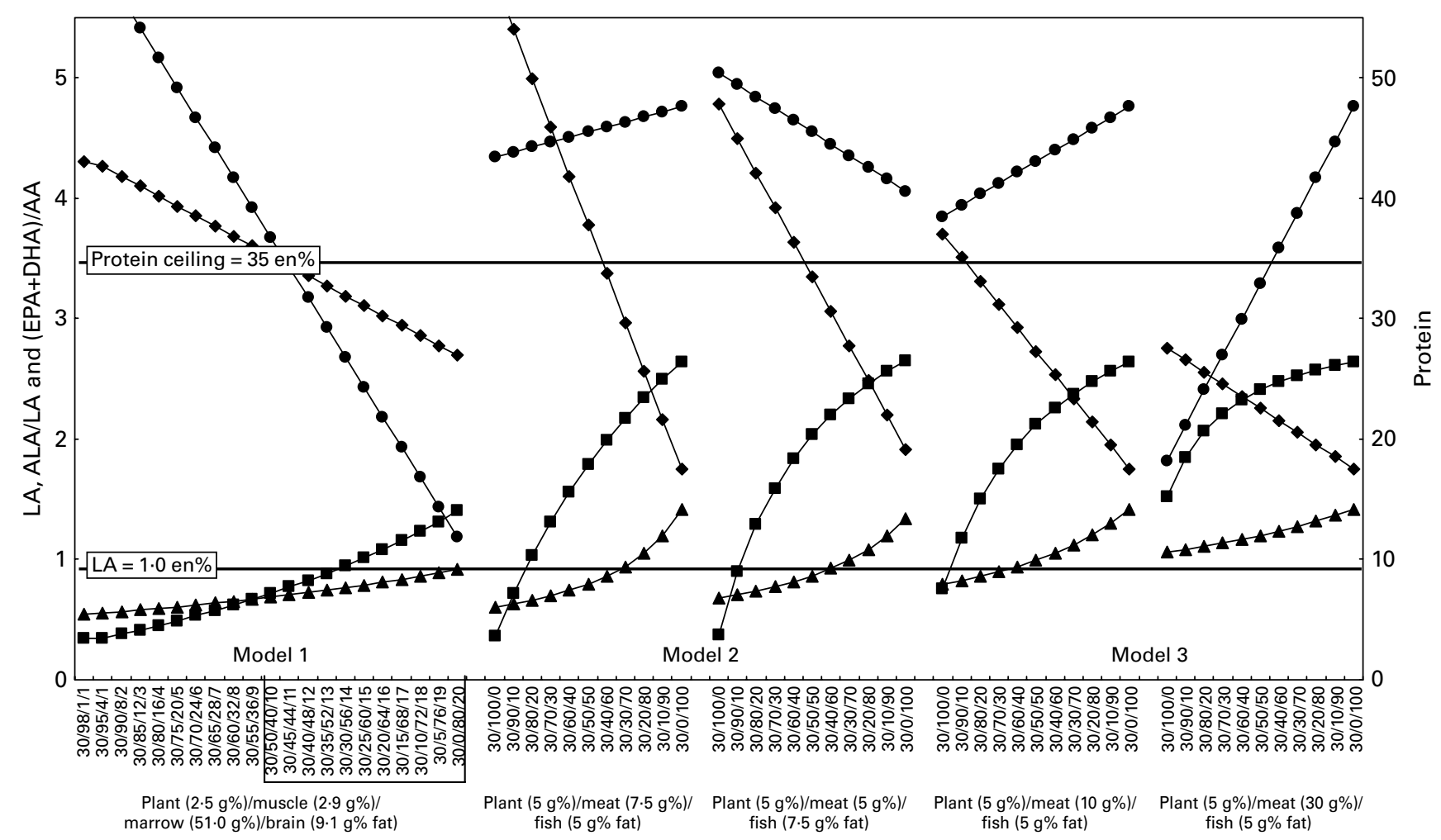

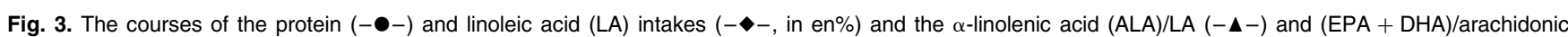
acid (AA) ratios (- - , in $\mathrm{g} / \mathrm{g}$ ) with changing composition of animal food at a $30 / 70 \mathrm{en} \% / \mathrm{en} \%$ plant/animal subsistence ratio. For legend: see Figure 2.

Table 4 presents the medians (ranges) from all the investigated models together with the original data from the savannah diet as used by Eaton et al. ${ }^{(26)}$ for a $65 / 35 \mathrm{en} / \mathrm{en} \%$ plant/animal subsistence ratio and from Cordain et al. ${ }^{(27)}$ for a 45/55 en/en\% plant/animal subsistence ratio. All the data presented from Model 1 complied with the protein and LA constraints and met the EPA + DHA recommendation. All the data presented from Models 1-4 (Table 4) complied with the protein and LA constraints, and after application of these constraints, all the models also met the EPA + DHA recommendation.

\section{Model outcomes}

Model 1, selective hunter-gatherer/scavenger savannah diet. All the models met the EPA + DHA recommendation. It was found that with the exception of the $70 / 30$ en $\% /$ en $\%$ plant/animal subsistence ratio, all the investigated dietary options were limited by the $35 \mathrm{en} \%$ protein ceiling. This ceiling was reached when more than $45 \mathrm{en} \%$ of animal food was consumed as muscle meat. LA, AA and EPA + DHA intakes increased with decreasing intakes of plants, whereas ALA intakes decreased. At low intakes of plants, only those options with high intakes of bone marrow and brain, relative to muscle, fulfilled the $<35 \mathrm{en} \%$ protein constraint. At $70 \mathrm{en} \%$ intake from plants, $0 \mathrm{en} \%$ from muscle, $80 \mathrm{en} \%$ from bone marrow and $20 \mathrm{en} \%$ from brain, the intakes of bone marrow and brain would be 141 and $148 \mathrm{~g} / \mathrm{d}$, respectively. At the lowest intake of plants (i.e. $30 \mathrm{en} \%$ ) and at contributions of muscle, bone marrow and brain ranging from 0 to 50,40 to 80 and 10 to $20 \mathrm{en} \%$, respectively, the intakes on a weight basis of muscle, bone marrow and brain ranged from 0 to 867,189 to 344 and 181 to $328 \mathrm{~g} / \mathrm{d}$, respectively. LA intakes ranged from 2.83 to $3.52 \mathrm{en} \%$ in a $70 \mathrm{en} \%$ plant food diet and from 2.69 to $4.30 \mathrm{en} \%$ in a $30 \mathrm{en} \%$ plant food diet. With protein and LA complying with their recommendations, the intakes of EPA + DHA ranged from 0.88 to $1.63 \mathrm{~g} / \mathrm{d}$ at $70 \mathrm{en} \%$ plant food and from 2.20 to $2.98 \mathrm{~g} / \mathrm{d}$ at $30 \mathrm{en} \%$ plant food, while the (EPA + DHA)/AA ratios ranged from 0.41 to 1.41 and 0.77 to $1.40 \mathrm{~g} / \mathrm{g}$, respectively.

Model 2, non-selective hunter-gatherer/scavenger savannah/ aquatic diet. In this model, several plant/(meat/fish) ratios that were investigated at different fat percentages fulfilled the two constraints. All the options that met these constraints also met the EPA + DHA recommendation. Also here, the options became restricted by the protein ceiling, when the intake of animal food increased. Reaching the protein ceiling proved to be dependent on the fat contents of the meat and fish consumed, as can be concluded from Figs. 2 and 3. Not unexpectedly, these indicate that the lower the fat content of the animal foods (i.e. the leaner the meat), the sooner the protein ceiling is reached. Since LA is relatively abundant in plants, muscle and liver, but not in fish (Table 1), the constraint for LA $(>1.0 \mathrm{en} \%)$ could not be reached if $70 \mathrm{en} \%$ was consumed as animal food that is composed of high-fat meat (e.g. $100 \mathrm{en} \%$ meat with $\geq 7.5 \mathrm{~g} \%$ fat) in combination with low-fat plants (e.g. $2.5 \mathrm{~g} \%$ fat) (Fig. 2, left panel for Model 2). For Model 2, Figs. 2 and 3 show that the slope of the (EPA + DHA)/AA curve steepens with increasing fat content in fish and decreasing fat content in meat. This steepening of the (EPA + DHA)/AA curve takes place at an increase of both the EPA + DHA and AA intakes, indicating that the 
(Medians and ranges)

\begin{tabular}{|c|c|c|c|c|c|c|c|c|c|c|}
\hline \multirow[b]{2}{*}{ Nutrient } & \multirow{2}{*}{$\begin{array}{c}\text { Meat based } \\
\text { (non-selective; } \\
\text { Eaton et al. }{ }^{(26)} \text { ) } \\
\text { Median }\end{array}$} & \multirow{2}{*}{$\begin{array}{c}\text { Meat based } \\
\text { (non-selective; } \\
\text { Cordain et al. }{ }^{(27)} \text { ) } \\
\text { Median }\end{array}$} & \multicolumn{2}{|c|}{$\begin{array}{c}\text { Meat based } \\
\text { (selective; Model 1) }\end{array}$} & \multicolumn{2}{|c|}{$\begin{array}{c}\text { Fish/meat based } \\
\text { (non-selective; Model 2) }\end{array}$} & \multicolumn{2}{|c|}{$\begin{array}{l}\text { Fish/meat based } \\
\text { (selective; Model 3) }\end{array}$} & \multicolumn{2}{|c|}{$\begin{array}{c}\text { Fish based } \\
\text { (non-selective; Model 4) }\end{array}$} \\
\hline & & & Median & Range & Median & Range & Median & Range & Median & Range \\
\hline \multicolumn{11}{|c|}{ Animal/plant subsistence ratio } \\
\hline $\begin{array}{l}\text { Plant/animal } \\
\text { (en\%/en\%) }\end{array}$ & $65 / 35 \dagger$ & $45 / 55 \ddagger$ & $50 / 50$ & $70-30 / 30-70$ & $50 / 50$ & $70-30 / 30-70$ & $55 / 45$ & $70-30 / 30-70$ & $57 / 43$ & $70-30 / 30-70$ \\
\hline $\begin{array}{l}\text { Meat/fish } \\
\quad(\mathrm{en} \% / \mathrm{en} \%)\end{array}$ & $100 / 0$ & $100 / 0$ & $100 / 0$ & & $60 / 40$ & $0-100 / 100-0$ & $58 / 52$ & $0-100 / 100-0$ & 0/100 & \\
\hline $\begin{array}{l}\text { Muscle/marrow/brain } \\
\text { (en\%/en\%) }\end{array}$ & - & - & $30 / 56 / 14$ & $98 / 1 / 1-0 / 60 / 20$ & - & - & $20 / 64 / 16$ & $50 / 40 / 10-0 / 80 / 20$ & & \\
\hline Plants (g/d) & $1653 \S$ & 988 & 1607 & $804-1875$ & 1257 & $539-1875$ & 1078 & $539-1257$ & 1257 & $534-1875$ \\
\hline Meat $(\mathrm{g} / \mathrm{d})$ & $890 \S$ & 1031 & 695 & $288-1213$ & 360 & $0-1028$ & 128 & $0-411$ & 0 & - \\
\hline Fish $(g / d)$ & 0 & - & 0 & & 381 & $0-1243$ & 681 & $357-952$ & 867 & $533-1243$ \\
\hline \multicolumn{11}{|l|}{ Macronutrients } \\
\hline Energy (kJ/d) & $12500 \dagger$ & $12500 \ddagger$ & 12500 & & 12500 & & 12500 & & 12500 & \\
\hline Protein (en\%) & $37 \|$ & $30 \ddagger$ & 25 & $8-35$ & 29 & $22-35$ & 27 & $16-35$ & 29 & $22-35$ \\
\hline From plants & 9.2 & 5.4 & 8.4 & $4-10$ & 8.4 & $4-10$ & 7.0 & $4-10$ & 7.7 & $4-10$ \\
\hline From animals & 29 & 25 & 16.9 & $0-32$ & 21 & $14-40$ & 19 & $6-29$ & 22 & $13-31$ \\
\hline Carbohydrate (en\%) & $41 \|$ & $34 \ddagger$ & 40 & $20-47$ & 40 & $19-48$ & 40 & $20-47$ & 39 & $19-48$ \\
\hline Fat $(\mathrm{en} \%)$ & $22 \|$ & $36 \ddagger$ & 39 & $21-72$ & 30 & $20-46$ & 34 & $25-62$ & 34 & $20-46$ \\
\hline Protein $(\mathrm{g} / \mathrm{d})$ & 236 & 191 & 160 & $51-223$ & 185 & $140-223$ & 172 & $102-223$ & 185 & $140-223$ \\
\hline From plants & 609 & - & 54 & $26-64$ & 54 & $27-63$ & 45 & $27-63$ & 49 & $26-64$ \\
\hline From animals & $191 \rrbracket$ & - & 108 & $0-204$ & 134 & $92-253$ & 119 & $38-185$ & 140 & $83-198$ \\
\hline Carbohydrate (g/d) & 294 & 243 & 267 & $144-337$ & 287 & $136-345$ & 287 & $144-337$ & 280 & $136-344$ \\
\hline Fat $(g / d)$ & 70 & 114 & 124 & $67-229$ & 95 & $64-146$ & 108 & $79-197$ & 108 & $64-146$ \\
\hline \multicolumn{11}{|l|}{ Essential fatty acids } \\
\hline $\operatorname{ALA}(18: 3 n-3, \mathrm{~g} / \mathrm{d})$ & $12.6 \S$ & $15 \cdot 0$ & 11.9 & $7.73-13.4$ & 13.5 & $6.57-18.5$ & 14.8 & $8.63-17.4$ & $12 \cdot 6$ & $6.57-17.0$ \\
\hline EPA $(20: 5 n-3, \mathrm{~g} / \mathrm{d})$ & $0.39 \S$ & 0.71 & 0.38 & $0.14-0.59$ & 1.74 & $0.56-6.61$ & 1.41 & $0.30-2.80$ & 3.45 & $1.41-6.61$ \\
\hline DPA $(22: 5 n-3, g / d)$ & $0.42 \S$ & 0.96 & 0.52 & $0.20-0.90$ & 1.53 & $0.66-4.71$ & 1.03 & $0.20-1.93$ & $2 \cdot 36$ & $0.89-4.71$ \\
\hline DHA $(22: 6 n-3, \mathrm{~g} / \mathrm{d})$ & $0.27 \S$ & 0.41 & 1.35 & $0.29-2.84$ & 4.30 & $0.32-21.7$ & 4.36 & $0.81-8.79$ & 10.8 & $3.93-21.7$ \\
\hline EPA + DHA (g/d) & $0.66 \S$ & $1 \cdot 12$ & 1.70 & $0.87-2.98$ & $6 \cdot 10$ & $0.88-28.3$ & 5.83 & $1.38-11.6$ & $14 \cdot 2$ & $5 \cdot 34-28 \cdot 3$ \\
\hline LCP $n-3(\mathrm{~g} / \mathrm{d})$ & 1.61 & 2.01 & $2 \cdot 26$ & $1.53-3.52$ & 7.64 & $1.47-33.9$ & 6.89 & $1.76-13.8$ & $17 \cdot 0$ & $6.33-33.9$ \\
\hline$n-3(\mathrm{~g} / \mathrm{d})$ & 17.5 & $20 \cdot 3$ & $16 \cdot 6$ & $12 \cdot 2-18 \cdot 5$ & 25.9 & $16 \cdot 0-44 \cdot 4$ & $25 \cdot 2$ & $14.3-31.9$ & $34 \cdot 1$ & $22 \cdot 1-44 \cdot 4$ \\
\hline LA $(18: 2 n-6, g / d)$ & $8.84 \S$ & $14 \cdot 3$ & 9.98 & $8 \cdot 60-11 \cdot 2$ & $11 \cdot 3$ & $5 \cdot 53-19 \cdot 8$ & 9.83 & $7 \cdot 20-12 \cdot 2$ & 7.46 & $5.53-9.96$ \\
\hline AA $(20: 4 n-6, g / d)$ & $1.81 \S$ & 2.41 & 1.81 & $1.15-2.77$ & 3.65 & $1.69-10.7$ & 2.84 & $1.15-4.61$ & 5.46 & $2.14-10.7$ \\
\hline LCP $n-6(g / d)$ & 2.23 & 2.81 & 2.54 & $2.03-3.99$ & 5.09 & $2.00-17.4$ & 4.51 & $1.91-7.64$ & 8.84 & $3.41-17.4$ \\
\hline$n-6(\mathrm{~g} / \mathrm{d})$ & 14.8 & 17.9 & 13.4 & $11 \cdot 7-15 \cdot 6$ & 17.9 & $10 \cdot 9-25 \cdot 9$ & $15 \cdot 2$ & $12 \cdot 9-16 \cdot 2$ & 17.6 & $10 \cdot 9-24 \cdot 2$ \\
\hline $\operatorname{LCP}(g / d)$ & 3.75 & 4.70 & 4.75 & $3.46-7.46$ & 12.5 & $3 \cdot 38-51 \cdot 3$ & $11 \cdot 2$ & $3.77-21.2$ & $25 \cdot 8$ & $9.74-51.3$ \\
\hline ALA/LA $(g / g)$ & 0.70 & 1.04 & $1 \cdot 12$ & $0.70-1.56$ & 1.25 & $0.61-1.79$ & 1.47 & $0.93-1.75$ & 1.64 & $1.19-1.79$ \\
\hline$(E P A+D H A) / A A(g / g)$ & 0.49 & 0.47 & 0.95 & $0.49-1.41$ & 1.82 & $0.36-2.66$ & $2 \cdot 13$ & $0.78-2.58$ & 2.60 & $2 \cdot 45-2 \cdot 66$ \\
\hline LCP $n-3 / L C P ~ n-6(\mathrm{~g} / \mathrm{g})$ & 0.72 & 0.72 & 0.84 & $0.74-0.92$ & 1.56 & $0.67-1.96$ & 1.86 & $0.22-3.07$ & 1.92 & $1.83-1.96$ \\
\hline$n-3 / n-6(g / g)$ & 1.19 & $1 \cdot 13$ & 1.22 & $0.79-1.59$ & 1.50 & $0.66-2.05$ & 1.69 & $1.01-2.01$ & 1.94 & $1.82-2.05$ \\
\hline ALA $(18: 3 n-3$, en\%) & 4.0 & $4 \cdot 7$ & 3.7 & $2 \cdot 4-4 \cdot 2$ & $4 \cdot 2$ & $2 \cdot 1-5 \cdot 8$ & 4.7 & $2 \cdot 7-5 \cdot 5$ & 4.0 & $2 \cdot 1-5 \cdot 3$ \\
\hline LCP $n-3(\mathrm{en} \%)$ & 0.5 & 0.6 & 0.7 & $0.5-1.1$ & 2.4 & $0.5-11$ & 2.9 & $3.9-4.9$ & 2.9 & $3.9-4.9$ \\
\hline LA $(18: 2 n-6$, en\%) & $2 \cdot 8$ & 4.5 & 3.1 & $2.7-3.5$ & 3.6 & $1 \cdot 7-6 \cdot 2$ & $3 \cdot 1$ & $2 \cdot 3-3 \cdot 8$ & $2 \cdot 3$ & $1 \cdot 7-3 \cdot 1$ \\
\hline LCP $n-6(\mathrm{en} \%)$ & 0.7 & 0.9 & 0.8 & $0.6-1.3$ & 1.6 & $0.6-5.5$ & 1.4 & $0.6-2.4$ & $2 \cdot 8$ & $1 \cdot 1-5.5$ \\
\hline \multicolumn{11}{|c|}{ Other fatty acids and cholesterol } \\
\hline SFA $(g / d)$ & 31.7 & 38.8 & $36 \cdot 3$ & $23 \cdot 0-56 \cdot 1$ & $38 \cdot 1$ & $21 \cdot 8-59 \cdot 1$ & 36.4 & $31.6-51.6$ & 38.0 & $21.8-53.9$ \\
\hline MUFA (g/d) & 23.4 & 29.2 & 58.8 & $11.5-124$ & $23 \cdot 6$ & $9 \cdot 90-50 \cdot 1$ & 41.3 & $14.5-109$ & 17.9 & $9 \cdot 90-26.5$ \\
\hline PUFA (g/d) & $29 \cdot 8$ & 34.4 & 27.2 & $25 \cdot 7-26 \cdot 2$ & 40.2 & $26 \cdot 9-66 \cdot 6$ & $36 \cdot 4$ & $26 \cdot 4-43 \cdot 9$ & $48 \cdot 3$ & $29.5-66.6$ \\
\hline $\mathrm{P} / \mathrm{S}$ ratio $(\mathrm{g} / \mathrm{g})$ & $1.40 \|$ & $1 \cdot 10$ & 0.75 & $0.46-1.23$ & 1.07 & $0.68-1.37$ & 1.05 & $0.58-1.34$ & 1.30 & $1.23-1.37$ \\
\hline Cholesterol $(\mathrm{mg} / \mathrm{d})$ & $480 \|$ & 830 & 3138 & $651-6910$ & 498 & $321-748$ & 914 & $430-3107$ & 523 & $321-748$ \\
\hline
\end{tabular}


EPA + DHA content of the various dietary options, and not the AA content, is the most variable factor in determining the (EPA + DHA)/AA ratio in Model 2.

Model 3, selective hunter-gatherer/scavenger savannah/ aquatic diet. Model 3 combines the favourable foraging strategies for hunting, gathering and scavenging from Models 1 and 2. All the dietary options that met the constraints for protein and LA also met the EPA + DHA recommendation (Table 4). The protein ceiling becomes limiting at the combination of low plant intake and the consumption of low-fat meat, as can be concluded from Fig. 3 (left panel). This limitation became circumvented by the consumption of high-fat meat (Fig. 3, right panel), while it also becomes circumvented by the consumption of highfat plants and fish (data not shown).

Model 4, non-selective hunter-gatherer/scavenger aquatic diet. In this model, $55 \%$ of the investigated plant/fish ratios that were investigated at different fat percentages fulfilled the protein constraint. All the options meeting this constraint also met the LA constraint and the EPA + DHA recommendation.

\section{Discussion}

We estimated the medians and ranges of the dietary macronutrient and fatty acid compositions for multiple foraging strategies ascribed to Paleolithic hunter-gatherer/scavengers living in the savannah, the land-water ecosystem and the combinations of both. Most importantly, we found that the macronutrient composition averaged $25-29$ en\% (range $8-35$ ) from protein, $39-40$ en\% (range 19-48) from carbohydrate and 30-39 en\% (range 20-72) from fat. These outcomes indicate moderate-to-high protein and fat intakes, with moderate carbohydrate intakes. Compared with the current Western intakes and recommendations, the fatty acid composition was high in SFA (range of medians 11.4-12.0; total range $6 \cdot 8-19 \mathrm{en} \%$ ), and moderate-to-high in MUFA (5.6-18.5; 3.1-39 en\%) and PUFA (8.6-15.2; $8 \cdot 1-21$ en\%). The PUFA were high in ALA $(3 \cdot 7-4 \cdot 7 ; 2 \cdot 1-5 \cdot 8$ en $\%)$, low in LA (2.3-3.6; 1.7-6.2 en\%), and high in LCP (4.75-25.8; $3.38-51.3 \mathrm{~g} / \mathrm{d})$, both LCP $n-3(2.26-17.0 ; 1.47-33.9 \mathrm{~g} / \mathrm{d})$ and LCP $n-6(2.54-8.84 ; 1.91-17.4 \mathrm{~g} / \mathrm{d})$. Consequently, the ALA/LA ratio $(1.12-1.64 ; 0.61-1.79 \mathrm{~g} / \mathrm{g})$ was remarkably higher compared with the present ALA/LA ratio (ALA/ $\left.\mathrm{LA}=0.09^{(81)}\right)$. The LCP $n$-3/LCP $n$-6 ratio $(0.84-1.92$; $0.22-3.07 \mathrm{~g} / \mathrm{g})$ was comparable to the current ratio $\left(0.85^{(81)}\right)$, but the absolute intakes of both LCP $n-3$ and LCP $n-6$ were remarkably higher.

\section{Our ecological niche}

From 1.9 million to 200000 years ago, hominins tripled their brain mass relative to body mass, which is usually expressed in terms of the encephalisation quotient. The predominantly vegetarian Australopithecines were estimated to have an encephalisation quotient of 1.23-1.92, while the Homo genus has an encephalisation quotient of $1 \cdot 41-4 \cdot 26^{(9)}$. The Ardipithecus ramidus may have persisted in a more closed wooded habitat ${ }^{(82)}$, but the Australopithecines are assumed to have left the forest to enter the open ${ }^{(83)}$, where they were able to introduce more energy-dense animal food into their diets at 
the expense of energy-poor plants ${ }^{(84)}$. Improvement of dietary density and quality may have enabled an increase in brain size, while it also provided the higher energy needs for the expanding, metabolically expensive, brain. It has been hypothesised that the brain growth was preceded by the development of a sizeable adipose tissue compartment ${ }^{(85)}$ to ensure continuous availability of energy, which is also known as 'the survival of the fattest ${ }^{(86)}$. Other physical adjustments might have been necessary, since the adult primate brain usually consumes $8-9 \%$ of the total RMR, while this amounts to $20-25 \%$ in anatomically modern humans ${ }^{(87)}$. One of these adjustments is the loss of muscle ${ }^{(87)}$. Additional energy reallocation might have come from adjustment of the gastrointestinal tract. The size of our current gastrointestinal tract comprises only $60 \%$ of that expected for a similarly sized primate, probably because of its devotion to easily digested energy-dense foods rather than a fibre-rich, bulky and consequently energy-poor vegetarian diet that requires a large colon $^{(88)}$. The trade-off with the energetically expensive gastrointestinal tract is also known as the 'expensive tissue hypothesis' as proposed by Aiello \& Wheeler ${ }^{(89)}$.

Brain expansion necessitates not only energy for its growth and maintenance but also the availability of building blocks such as AA and DHA, and many other factors, collectively referred to as 'brain-selective nutrients' (or 'brain food') ${ }^{(9,15)}$. The question is what ecological niche would have supported the growth of our brain and especially the increment of DHA within a species characterised by the low capacity to synthesise DHA but high DHA needs. Comparison of the brain ethanolamine phosphoglycerols of forty-two species shows an almost identical LCP pattern that, independent of encephalisation quotient, is composed of about equal percentages of AA and $\mathrm{DHA}^{(9)}$. A low dietary DHA intake by rats lowers DHA in the frontal cortex, down-regulates DHA turnover and increases AA turnover, which is a condition that has been related to neuroinflammation ${ }^{(90)}$. Accretion of DHA in the brain of newborn baboons ${ }^{(91)}$ and newborn humans ${ }^{(92)}$ depends on the postnatal dietary DHA supply during the brain growth spurt, which occurs from the last trimester up to 2 years after birth in humans. An experiment with diets varying in ALA, LA, AA and DHA administered to female mice from $3 \mathrm{~d}$ before conception showed that, in contrast to the relatively static maternal brain, the growing fetal brain is extremely sensitive to low maternal dietary $\mathrm{DHA}^{(93)}$. Many RCT that aimed at the consequences of low DHA in the brain of human newborns have been performed. The results are at most inconclusive $^{(22)}$, but various recommendations for DHA intakes by formula-fed and breast-fed infants have been issued ${ }^{(94)}$.

Taken the afore-mentioned results together, it seems clear that the evolution of our brain growth is unlikely to have been hampered by poor availability of dietary DHA, which is abundant in the brain of the animals that we might have consumed in the savannah, but notably the food that is available in a land-water ecosystem. Our derivation from the land-water ecosystem is strengthened by the African ${ }^{(9)}$ and European $^{(10)}$ fossil records and the many pathophysiological consequences of a low DHA status and a low intake of 'brain food' in general. The many indications for the exploitation of aquatic resources by early hominins date back as far as 2.3-2.0 million years ago in Semliki River, Zaire ${ }^{(10)}$. Collection of aquatic foods is still a daily practice in East Africa, and picking up, clubbing, spearing or killing aquatic animals from a distance ${ }^{(95)}$ seem to be much easier than either scavenging or hunting game on the Serengeti plains ${ }^{(9)}$. Contrary to the popular belief, our ancient ancestors did not need fishing gear to benefit from the abundance of LCP $n-3$ and LCP $n-6$ in such ecosystems, where it is relatively easy to hunt and gather anything ranging from spawning (cat)fish, shellfish, crustaceans and cephalopods (lobster, crab, shrimp, squid, octopus, etc.) to sea urchins, amphibians, birds and reptiles and their respective eggs ${ }^{(10)}$. All of these species ultimately receive their LCP $n-3$ from plankton via the local food chain ${ }^{(96)}$. We seem to have experienced a diminishing consumption of food from this ecosystem since the Out-ofAfrica diaspora ${ }^{(97)}$. For instance, analysis of ${ }^{13} \mathrm{C}$-collagen from bones ${ }^{(98)}$ showed a sharp shift from a marine-based diet to a terrestrial-based diet in Britain at the onset of the Neolithic (4000 years ago). Also the consumption of animal brain is conceivable, but may not solely be responsible because of its lack of many other constituents of 'brain food', notably iodine ${ }^{(16)}$. Abundantly available iodine is characteristic for marine ecosystems. The wide occurrence of iodine deficiency in people living in the inland suggests that hominin encephalisation likely occurred in the land-water ecosystem. Although some traditional inland hunter-gatherers might circumvent this problem by organ consumption, including the iodine-rich thyroid of their prey, many 'modern' humans, living far from the land-water ecosystem, have abolished organ consumption and may consequently suffer from iodine deficiencies if the element is not added to common salt.

\section{Macronutrients}

Total protein intake from the presumed Paleolithic diet contributed 25-29 en\% of the daily energy intake (range 8-36), which is remarkably higher than the average present-day intake of $15 \mathrm{en} \%$ in the $\mathrm{USA}^{(99)}$, at the high range of $10-35$ en $\%$ as recommended by RDA of the National Institute of Medicine ${ }^{(100)}$, somewhat lower than was reported by Eaton et $a .^{(26)}(37 \mathrm{en} \%)$ and comparable to the $30 \mathrm{en} \%$ (range 19-35) as reported by Cordain et al. ${ }^{(27)}$. The current estimate may be rated as a moderate-to-high-protein diet. On a weight basis, the protein intake from a $12500 \mathrm{~kJ}$ Paleolithic diet was estimated at $160-185 \mathrm{~g} / \mathrm{d}$ (range 51-223) (RDA for adults $\left.46-52 \mathrm{~g} / \mathrm{d}^{(100)}\right)$, of which animal protein was $108-140 \mathrm{~g} / \mathrm{d}$, and plant protein was $45-54 \mathrm{~g} / \mathrm{d}$. By contrast, modern humans consume less than one-half that amount of animal protein (i.e. $64-68 \mathrm{~g} / \mathrm{d}$ ), and about two-thirds that amount of plant protein (i.e. $32-36 \mathrm{~g} / \mathrm{d}$ ) from an average diet of $10850 \mathrm{~kJ}$ for men and $7312 \mathrm{~kJ}$ for women ${ }^{(101,102)}$. Our models show that a Paleolithic diet results in a moderate carbohydrate intake of $39-40$ en\% (range 19-48), which is similar to the intake of $41 \mathrm{en} \%$ in Eaton's model ${ }^{(26)}$. The $34 \mathrm{en} \%$ (range 22-40) intake in Cordain's model ${ }^{(27)}$ was somewhat lower than current estimates, because of an assumed higher animal food intake at the expense of carbohydrate-rich plants. Current carbohydrate intakes in affluent countries average $49 \mathrm{en} \%$ for men and $52 \mathrm{en} \%$ for women ${ }^{(99)}$, while the recommendations range from 40 to 65 en ${ }^{(100)}$. From 1971 to 2000 , carbohydrate intakes in the USA have increased (men, from 42 to 49 and women, from 
45 to 52 en $\%$ ) at the expense of fat (men, from 37 to 33 and women, from 36 to 33 en\%), saturated fat (men, from 14 to 11 and women, 13 to $11 \mathrm{en} \%$ ) and protein (men, from 17 to 16 and women, from 17 to $15 \mathrm{en} \%)^{(99)}$. This may at least partially originate from the advice to lower the fat intake, especially SFA, and to replace by intake of carbohydrates ${ }^{(100)}$. In our models, a moderate-to-high 30-39 en\% (range 20-72) was obtained from fat, which is comparable with the current Western intakes of about $33 \mathrm{en}{ }^{(99)}$, at the high range of the recommended $20-35 \mathrm{en} \%^{(100)}$, higher than the $22 \mathrm{en} \%$ fat intake in the model of Eaton et al. ${ }^{(26)}$, but comparable with the 36 en\% (range 28-58 en\%) in the model of Cordain et al. ${ }^{(27)}$.

Beasley et al. ${ }^{(103)}$ showed that a carbohydrate intake in the low range of the recommended en\% (i.e. $48 \mathrm{en} \%$ ), together with a protein intake $(25 \mathrm{en} \%)$ at the high range of recommended en $\%$ and a fat intake at the recommended average en $\%(27 \mathrm{en} \%)$ reduces self-reported appetite, compared with diets with higher carbohydrates (58 en\%) or high unsaturated fat $(37 \mathrm{en} \%)$. In addition, compared with three other diets, the low-carbohydrate/high-protein 'Atkins' diet proved superior for weight loss within a 1-year randomised trial performed with overweight premenopausal women ${ }^{(104)}$. The effect is likely to be caused by better dietary adherence ${ }^{(105)}$, which was obviously superior in those receiving the high-protein Atkins diet ${ }^{(104,105)}$. A high-protein diet induces satiation via the anorectic hormone peptide $\mathrm{YY}^{(106)}$ and satiety by its high diet-induced energy expenditure. The latter amounts to $0-3 \%$ for fat, 5-10\% for carbohydrate and $20-30 \%$ for protein, and is needed for intestinal absorption, initial metabolism and storage of the nutrient products that are not immediately utilised. The concomitant oxygen consumption and rise in body temperature lead to a feeling of oxygen deprivation, which promotes satiety $^{(107)}$. Similar appetite-controlling effects may be expected from the Paleolithic diets (Table 4), which contain even lower carbohydrate, but higher fat, compared with the low-carbohydrate/high-protein diet as used by Beasley et $a{ }^{(103)}$. The Paleolithic diets have, however, higher carbohydrate, similar protein and lower fat, compared with the 'Atkins diet' as used by Gardner et al. ${ }^{(104)}$. The high volume of the Paleolithic diet, that is partially composed of bulky fibre in vegetables and fruits, may also enhance satiety and satiation ${ }^{(108)}$.

The weight-controlling effect of a Paleolithic diet was indeed shown by Osterdahl et al. ${ }^{(109)}$, who in an uncontrolled study with healthy adults, demonstrated a decrease in weight, BMI and waist circumference after 3 weeks ad libitum consumption of a Paleolithic-like diet (i.e. $6633 \mathrm{~kJ} / \mathrm{d}$; carbohydrate 40 , protein 24 , fat $36 \mathrm{en} \%$ ), compared with their baseline usual diet $(10377 \mathrm{~kJ} / \mathrm{d}$; carbohydrate 54 , protein 14 , fat 30 en\%). Similarly, improved reduction in weight, BMI and waist circumference were shown in the study of Jonsson et $a l .{ }^{(110)}$, who performed a $2 \times 3$ months cross-over study in type 2 diabetic patients receiving a Paleolithic diet $(6620 \mathrm{~kJ} / \mathrm{d}$; carbohydrate 32 , protein 24 , fat $39 \mathrm{en} \%)$ or a Diabetes diet $(7864 \mathrm{~kJ} / \mathrm{d}$; carbohydrate 42 , protein 20 , fat $34 \mathrm{en} \%)$. In a randomised trial in patients with IHD plus glucose intolerance or type 2 diabetes, Lindeberg et al. ${ }^{(111)}$ showed a reduced energy intake after ad libitum consumption of a Paleolithic diet $(5628 \mathrm{~kJ} / \mathrm{d}$; carbohydrate 40 , protein 28 , fat 27 en\%) compared with an ad libitum Mediterranean-like Consensus diet $(7517 \mathrm{~kJ} / \mathrm{d}$; carbohydrate 52 , protein 21 , fat $25 \mathrm{en} \%$ ). The studies of Osterdahl et al. ${ }^{(109)}$, Jonsson et al. ${ }^{(110)}$ and Lindeberg et al. ${ }^{(11)}$ suggest that the underlying reduced energy intake was due to improved appetite control. They may also have been accompanied by improved body composition, since studies on high protein intakes during body weight loss and subsequent maintenance have shown preserved or increased fat-free mass at the expense of fat mass, and an improved metabolic profile ${ }^{(107)}$. Contrary to widespread belief, high-protein diets do not have adverse effects on bone mass and especially if the diet is also rich in fruits and vegetables ${ }^{(112)}$. They are more likely to promote bone health and reduce the incidence of osteoporotic fractures ${ }^{(107)}$.

The current carbohydrate intake in affluent countries is not only high compared with that of our Paleolithic ancestors, but there is also a marked qualitative difference. In the era before the agricultural revolution, the majority of carbohydrates were derived from fresh fruits and vegetables, together with roots and tubers, and very little were derived from cereal grains or refined carbohydrates with high glycaemic indices (e.g. highly processed grains, sucrose and fructose $)^{(1)}$. For hunter-gatherers, wild honey provides the only type of the so-called 'empty calories' (high-energy food without essential amino acids, essential fatty acids or micronutrients), but it is only seasonably accessible and accounts for no more than $0.4-1.2 \mathrm{en} \%$ in the studied foragers $^{(3)}$. Food products with high glycaemic loads, especially when consumed in isolation, cause transient hyperinsulinaemia (which is associated with CHD) and postprandial hypoglycaemia (which is associated with increased hunger and lowered satiety) ${ }^{(113-115)}$. There is increasing evidence that carbohydrates, especially refined carbohydrates with high glycaemic indices, and food products with high glycaemic loads play important roles in the aetiology of the diseases associated with the metabolic syndrome, such as type 2 diabetes mellitus and $\mathrm{CHD}^{(113-115)}$.

Evidence for the beneficial effects of Paleolithic diets may also be derived from their influence on classical CHD risk factors. The uncontrolled study of Osterdahl et al. ${ }^{(109)}$ showed favourable effects on systolic blood pressure and plasminogen activator inhibitor-1, while the study of Jonsson et al. ${ }^{(110)}$ in type 2 diabetic patients resulted in lower $\mathrm{HbA}_{1 \mathrm{c}}$, TAG and diastolic blood pressure, and higher HDL-cholesterol, when compared with the Diabetes diet. The trial of Lindeberg et al. ${ }^{(11)}$ in patients with IHD showed a larger improvement in glucose tolerance, independent of decreased waist circumference, for a Paleolithic diet, when compared with a Mediterranean-like Consensus diet. In an uncontrolled trial, Frassetto et $a l^{(116)}$ showed that consumption of an isoenergetic Paleolithic type of diet $(11311 \mathrm{~kJ} / \mathrm{d}$; carbohydrate 38 , protein 30 , fat $32 \mathrm{en} \%$ ) for $10 \mathrm{~d}$ improved blood pressure, arterial distensibility, insulin sensitivity, and total, HDL- and LDL-cholesterol in healthy sedentary human subjects, when compared with their baseline usual diet $(9933 \mathrm{~kJ} / \mathrm{d}$; carbohydrate 44 , protein 18 , fat 38 en\%). Importantly, there were no statistically significant changes in energy intakes, activity levels and body weight, showing that the improved CHD risk profile was unrelated to weight reduction. 


\section{Dietary cholesterol}

Current recommendations for the intake of cholesterol range from 'as low as possible' to $<300 \mathrm{mg} / \mathrm{d}^{(100)}$. Estimated intakes from the models of Eaton et al. ${ }^{(26)}$ and Cordain et $a .^{(27)}$ (recalculated from our data) were 480 and $830 \mathrm{mg} / \mathrm{d}$, respectively, while the current estimates from Models 2-4 are 498, 914 and $523 \mathrm{mg} / \mathrm{d}$. The sizeable intakes of cholesterol in Models 1 and 3 are derived from very high amounts of cholesterol in brain $(2037 \mathrm{mg} /$ $100 \mathrm{~g})^{(33)}$ and marrow $(119.6 \mathrm{mg} / 100 \mathrm{~g})^{(117)}$, compared with an average amount of $65 \cdot 9^{(6)}$ in meat and $60.2 \mathrm{mg} / 100 \mathrm{~g}^{(33)}$ in fish. The estimated Paleolithic cholesterol intakes are well above the present intakes of $320 \mathrm{mg} / \mathrm{d}$ in the $\mathrm{USA}^{(118)}$ and the proclaimed 'high cholesterol intakes' of Japanese men $(446 \mathrm{mg} / \mathrm{d})$ and women $(359 \mathrm{mg} / \mathrm{d})^{(118)}$. Hunter-gatherers ${ }^{(119)}$ have low serum total cholesterol and LDL-cholesterol, typically ranging from 2.1 to 3.6 and 1.0 to $1.8 \mathrm{mmol} / 1$, respectively, that do not increase with age $^{(120)}$. The pastoral living Maasai have high intakes of fat (about $300 \mathrm{~g} / \mathrm{d}$ ), SFA and cholesterol (about $600 \mathrm{mg} / \mathrm{d}$ ) from both milk and meat. Yet they exhibit low serum total cholesterol (about $3.3 \mathrm{mmol} / \mathrm{l}$ ) with extensive atherosclerosis with lipid infiltration and fibrous changes of their aortas, together with intimal thickening of their coronary arteries. They are nevertheless virtually free from signs of CHD, they have smaller hearts, their blood pressure exhibits only a slight tendency to increase with age, they have low BMI, and they are remarkably fit ${ }^{(121)}$. The currently estimated cholesterol intakes by our ancient ancestors, and data from the Japanese and the Maasai do not support the limitation of dietary cholesterol intake to $300 \mathrm{mg}$ or 'as low as possible'. Cholesterol intakes above these recommendations might at most be disadvantageous by their interaction with other unfavourable changes in diet or lifestyle.

\section{Fatty acids}

SFA. The average (range) SFA intake from our reconstructed diets was $11.4(7 \cdot 2-18), 12 \cdot 0(6 \cdot 9-19), 11 \cdot 5$ $(9 \cdot 9-16)$ and $12 \cdot 0(6 \cdot 8-17)$ en\% for Models $1-4$, respectively. It is currently recommended to maintain the SFA intake 'as low as possible' and preferably below $10 \mathrm{en} \%$. The association that is usually presented to illustrate that SFA are hypercholesterolaemic ${ }^{(100)}$ is not only characterised by high inter-individual variation, but also by a slope that indicates that $1 \mathrm{en} \%$ SFA increases serum total and LDL-cholesterol by no more than 0.052 and $0.036 \mathrm{mmol} / 1$, respectively ${ }^{(122)}$. It was recently concluded that there is insufficient evidence that SFA is causally related to CHD risk ${ }^{(123)}$. Replacement of SFA by carbohydrates at low total fat intake might even be associated with greater CHD progression ${ }^{(124)}$.

A SFA (notably 16:0)-rich diet might only be hypercholesterolaemic in the context of a carbohydrate-rich diet. When carbohydrate is replaced by SFA, the increase in HDL-cholesterol is even higher compared with the replacement by MUFA or PUFA, although a significant decrease in the total cholesterol/HDL-cholesterol ratio is only observed when carbohydrates are replaced by PUFA and MUFA ${ }^{(125)}$. Volek et $a .^{(5)}$ not only showed that a SFA-rich carbohydraterestricted hypoenergetic diet (carbohydrate $12 \mathrm{en} \%$, fat
60 en $\%$, SFA $36 \mathrm{~g}$ ), compared with a hypoenergetic low-fat diet (carbohydrate $56 \mathrm{en} \%$, fat $34 \mathrm{en} \%$, SFA $12 \mathrm{~g}$; both $6281 \mathrm{~kJ}$ ), was superior in improving CHD risk factors but also showed that the subjects consuming the carbohydraterestricted SFA-rich diet had lower SFA in serum TAG and cholesteryl esters. It seems that a carbohydrate-rich diet prolongs circulatory exposure to SFA, causing a more intense interaction with toll-like receptors 4 and $2^{(126)}$, and thereby the release of proinflammatory cytokines such as monocyte chemoattractant protein-1 by adipocytes ${ }^{(127)}$. This mimicking of lipopolysaccharide action by SFA may trigger the hyperlipidaemia of sepsis ${ }^{(128)}$. It is increasingly acknowledged that metabolism and inflammation are intimately related ${ }^{(7)}$. The saturated lauric acid (12:0) exhibits a significant decrease in the total cholesterol/HDL-cholesterol ratio when $1 \mathrm{en} \%$ carbohydrates are replaced by lauric acid. Isoenergetic replacement of $10 \mathrm{en} \%$ of the average US diet by carbohydrates causes a higher increase of the total cholesterol/ HDL-cholesterol ratio than butter, while coconut oil decreases this ratio ${ }^{(125)}$. It is possible that our ancient ancestors living in tropical areas at the sea experienced all benefits of the combination of moderate carbohydrate and SFA intakes, and that they had abundant access to coconut-derived lauric acid, which is not only readily absorbed but also known for its anti-microbial properties ${ }^{(35)}$.

MUFA. In Models 2 and 4, the MUFA intakes (i.e. 7.4 and 5.6) are somewhat lower and equal to those from the models of Eaton (7.4) and Cordain (9.2), and on the low side, when compared with the worldwide intakes ranging from $8 \mathrm{en} \%$ in parts of China ${ }^{(129)}$ to more than $20 \mathrm{en} \%$ in the Mediterranean ${ }^{(130)}$. The average MUFA intake in Model 3 (i.e. $13.0 \mathrm{en} \%$ ) is similar to the $13 \mathrm{en} \%$ in the $\mathrm{USA}^{(74)}$, while the $18.5 \mathrm{en} \%$ in Model 1 is intermediate to this $13 \mathrm{en} \%$ and the high intakes in the Mediterranean. Populations consuming high-MUFA diets show low incidence of $\mathrm{CHD}^{(131)}$. However, although Japanese have low (9 en\%) MUFA intakes ${ }^{(129)}$, they also have low CHD risk $^{(132)}$. When replacing SFA by MUFA (11 en $\%)$ or carbohydrate (20 en $\%)$, MUFA provided a greater risk reduction in CHD than did carbohydrate ${ }^{(133)}$, while replacement of 1 en $\%$ carbohydrates with cis-MUFA caused a steep decrease in the total cholesterol/HDL-cholesterol ratio ${ }^{(125)}$. Taken together, it seems that MUFA are notably beneficial at isoenergetic low-to-moderate carbohydrate intakes.

$\alpha$-Linolenic acid and linoleic acid. In our models, the median ALA consumption and its range (Table 4) indicate that the mixing of fish and the introduction of selective consumption of meat into the savannah-derived Paleolithic diets as used by Eaton et al. and Cordain et al. ${ }^{(1,26-28)}$ increases the ALA intake to an average of 3.7-4.7 en $\%$ (range $2 \cdot 1-5 \cdot 8$ ). The models also show consistently low LA intakes $(2 \cdot 3-3 \cdot 6$, range $1 \cdot 7-6 \cdot 2 \mathrm{en} \%)$. After employment of the protein constraint, it proved unnecessary to additionally employ the 1.0 en\% LA constraint, since all of the remaining options within the four foraging strategies provided over 1.0 en $\%$ of LA.

The average daily intake of ALA for British omnivores was $0.4 \mathrm{en} \%(1.3 \mathrm{~g} / \mathrm{d})$ and $0.7 \mathrm{en} \%(2.2 \mathrm{~g} / \mathrm{d})$ for vegans ${ }^{(134)}$, which are both remarkably lower than the ALA intakes from the current and earlier Paleolithic diets as used by Eaton and Cordain. It is possible that the easily recycled ${ }^{(135)}$ dietary ALA constituted an important precursor for the synthesis of SFA, MUFA, 
cholesterol and ketone bodies for energy generation. The higher ALA intakes, compared with LA, might additionally explain why ALA is $\beta$-oxidised twice as fast as $\operatorname{LA}^{(136)}$. High ALA intakes from a Paleolithic diet might also be in line with the indications that ALA plays an important role in CHD prevention ${ }^{(137)}$. Anti-inflammatory effects of a high ALA intake include reductions in C-reactive protein, soluble intercellular adhesion molecule 1 , soluble vascular adhesion molecule 2 , IL-6, IL-1 $\beta$ and TNF- $\alpha^{(137,138)}$. Inconclusive evidence for the role of ALA in $\mathrm{CHD}^{(123)}$ might be explained by low intakes of ALA in combination with relatively high LA intakes, and it would be consistent with the stronger evidence linking increased ALA intake to low CHD risk, as observed for the subjects with low fish intakes ${ }^{(139)}$. The current models with ALA/LA ratios ranging from 0.61 to $1.79 \mathrm{~g} / \mathrm{g}$ (Table 4) reassert the unfavourable ALA/LA ratio in the Western diet, while such ratios were also used in many, if not all, intervention trials.

The LA intake of the models did not exceed $6 \cdot 2$ en\%. These outcomes are comparable with the calculated intakes from the models of Eaton et al. ${ }^{(26)}$ and Cordain et al. ${ }^{(27)}$. It is currently advised to augment the LA intake to 5-10 en\%, since it was concluded that aggregate data from RCT, case-control and cohort studies, and long-term animal feeding experiments indicated that these intakes reduce CHD risk $^{(140)}$. This, recently reinforced, advice by the American Heart Association has promoted the daily LA intake in Western countries to 4-9 en ${ }^{(71)}$. It also caused an increase in LA content in the breast milk to $>15 \mathrm{~g} \%$ in many Western countries ${ }^{(71)}$, which is significantly higher compared with the $4.2-5.2 \mathrm{~g} \%$ LA in the milk of traditionally consuming Tanzanian populations ${ }^{(35)}$. Our data indicate that such an LA status cannot be achieved without the consumption of refined vegetable oils. These have never been part of the diet on which our genome has been evolved to what it currently is. Correction of our current high CHD risk, by the introduction of nutrient intakes that have never been reached in the past, harbours the risk of introducing new imbalances. Employing the Hill criteria for causality, Mente et al. ${ }^{(123)}$ recently concluded that there is insufficient evidence that PUFA are causally related to $\mathrm{CHD}$ risk. In addition, it seems that the RCT with positive outcomes have been conducted at 11-21 en\% LA ${ }^{(140)}$ in which LA, sometimes also combined with increased ALA, fish or cod liver oil, replaced SFA. High intakes of LA, but not $\mathrm{AA}^{(141)}$, have been related to the aetiology of ulcerative colitis ${ }^{(142)}$, while LA intake was positively associated with a risk of severely depressed $\operatorname{mood}^{(143)}$ and homicide ${ }^{(21)}$. Studies with human endothelial cells suggest that LA might promote inflammation through activation of $\mathrm{NF}-\kappa \mathrm{B}$, and increased production of $\mathrm{TNF}-\alpha$, IL-6 and other inflammatory mediators ${ }^{(144)}$. The high prevalence of CHD, hypertension, type 2 diabetes mellitus and obesity in Israel, also referred to as the 'Israelian paradox'(145), might be related to the nationwide $8-12 \%$ higher PUFA intakes in Israel, compared with other Western countries. Ailhaud et $a l .{ }^{(71)}$ considered the decreasing dietary ALA/LA ratio, due to both an increase in LA and a decrease in ALA, in Western diets as a possible cause of obesity. Finally, it has become clear that the current high LA intake causes inhibition of the conversion of ALA to EPA and DHA, and thereby contributes to our currently low LCP $n-3$ status ${ }^{(146)}$.
Long-chain PUFA. In Models 2-4, the average sum of the intakes of the fish oil fatty acids EPA and DHA were 6.1 (range 0.88-28.3), 5.8 (range 1.38-11.6) and 14.2 (range 5.34-28.3) g/d. Because of the inclusion of food from the land-water ecosystem, these figures were much higher than those from the models of Eaton et al. ${ }^{(26)}$ and Cordain et al. ${ }^{(27)}$. The calculated average AA intakes of $3.65,2.84$ and $5.46 \mathrm{~g} / \mathrm{d}$ (ranges $1.69-10.7 ; 1.15-4.61 ; 2.14-10.7$ ), respectively, are also considerably higher compared with the intake of $1.81-2.41 \mathrm{~g} / \mathrm{d}$ (range $1.15-2.77$ ) of the savannah models.

In Model 2, the high LCP $n-3$ intake (median $7.64 \mathrm{~g} / \mathrm{d}$ ) is about half the intake of Inuit who have lifetime consumption of about $14 \mathrm{~g} \mathrm{LCP} n-3 / \mathrm{d}^{(147)}$, while in Model 4 the intake of $17.0 \mathrm{~g} \mathrm{LCP} n-3 / \mathrm{d}$ is even somewhat higher. The similarity between the LCP $n-3$ contents in the milk of Tanzanian mothers with high daily consumption of freshwater fish from Lake Victoria ${ }^{(35)}$ and the LCP $n-3$ contents in the milk of Canadian Inuit ${ }^{(148)}$ adds to this notion. Both the model outcomes are also in line with the estimates of Broadhurst et al. ${ }^{(11)}$ who calculated a daily intake of $29 \mathrm{~g}$ fish oil from a $9196 \mathrm{~kJ}$ diet by current native Africans living on the shore of Lake Malawi. With a $15 \mathrm{~g} \%$ average EPA + DHA content of the local fish, this would imply an intake of at least $6 \mathrm{~g} \mathrm{LCP}$ $n-3 / \mathrm{d}$, which is remarkably comparable with the intakes from Models 2 and 3. Crawford et al. ${ }^{(149)}$ estimated the daily intake of contemporary populations living at East African lakes (Lakes Nyasa and Turkana) at $1-4 \mathrm{~g}$ LCP $n-3$ and $0.5-1.0 \mathrm{~g}$ AA, respectively. All of the above-mentioned data suggest that in the Paleolithic era the intakes of EPA plus DHA greatly exceeded those currently recommended in Western societies $\left(450-500 \mathrm{mg} / \mathrm{d}^{(150,151)}\right)$, while also the AA intake was much higher than the present-day intake (about $200 \mathrm{mg} / \mathrm{d}^{(152)}$ ). Of interest is the lower (EPA + DHA)/AA ratio in African fish $(2.67 \mathrm{~g} / \mathrm{g})$ and consequently in the fish-based Paleolithic diets $(1.82-2.60 \mathrm{~g} / \mathrm{g})$, compared with Northern latitude fish ( $7.48 \mathrm{~g} / \mathrm{g}$ in cold water fish; $8.74 \mathrm{~g} / \mathrm{g}$ in European fish) (supplementary Table $\mathrm{S} 1$, available online only at http://journals. cambridge.org). It seems that many, if not all, intervention trials have been conducted with high (EPA + DHA)/AA ratios and certainly with relatively low absolute amounts of (EPA + DHA), while the intake of AA is usually ignored.

Our finding of high LCP intakes compared with the parent precursors LA and ALA and the knowledge that about $75 \mathrm{~g} \%$ of dietary LA and ALA is fully $\beta$-oxidised, even under extreme dietary LCP $n-3$ deficiency ${ }^{(135)}$, put the fatty acid desaturase (FADS) polymorphisms ${ }^{(153)}$, the concept of 'essential fatty acid deficiency' and also the $n-3 / n-6$ ratio into different perspectives. In contrast to the present, both the FADS polymorphisms and our difficulty to synthesise DHA might have been unimportant in the past. The chain elongation/desaturation pathway might not have been used at all, and LA and ALA deficiency might never have occurred. LA deficiency may be defined clinically in terms of symptoms such as a scaly dry skin and reproductive failure ${ }^{(154)}$, and ALA deficiency may be defined in terms of numbness, paraesthesia, weakness, pain and blurred vision ${ }^{(155)}$, while these deficiencies are biochemically characterised in terms of the accumulation of Mead acid ${ }^{(156)}$ or an increased Mead acid/AA ratio ${ }^{(136)}$. Neither symptoms nor Mead acid accumulation will occur when the intakes of AA and DHA are high, since these 
would inhibit fatty acid desaturase 1 and 2 activities. Also the specific function of LA in the synthesis of skin ceramides might be conserved and thereby skin's water barrier function, since dietary AA might in such circumstances become retroconverted to $\mathrm{LA}^{(157)}$. Retroconversion of DHA to $\mathrm{EPA}^{(158)}$ and possibly to ALA may also have occurred. Since under these conditions neither LA nor ALA would be essential, it was suggested $^{(136,159)}$ to consider AA and DHA as the genuine essential fatty acids. It would also imply that the presently employed constraint of $1.0 \mathrm{en} \%$ LA would be superfluous, and that the vigorously debated 'healthy' dietary $n-3 / n-6$ ratio $^{(97)}$ and the currently depicted (EPA + DHA)/AA ratio might have been unimportant in the past. AA, EPA and DHA might under these circumstances not compete with each other, but rather jointly compete with other fatty acids causing full saturation of tissues with LCP. This is currently not the case. For instance, Hsieh et al. ${ }^{(91)}$ showed that raising the DHA content in milk from 0.3 to $1.0 \mathrm{~g} \%$, both at $0.7 \mathrm{~g} \%$ AA, caused an increase in DHA in virtually all the investigated brain regions of the newborn baboon without affecting their AA contents. This suggests that newborns in Western countries have low DHA in brain, since many of their mothers have DHA contents in the range of $0.3 \mathrm{~g} \%$ in milk ${ }^{(34)}$. Finally, Angela Liou \& Innis ${ }^{(146)}$ recently showed that minimum LA requirements for AA synthesis are below $3.8 \mathrm{en} \%$, and suggested that the encountered twofold inter-individual variance of AA status might be due to FADS polymorphism. The estimated AA intakes by our Paleolithic ancestors suggest that neither of these problems might have been of importance in the past.

The suggested high dietary intakes of LCP, notably those of $\mathrm{AA}$, raise questions regarding their toxicities. In a recent study, it was concluded that estimated DHA intakes of up to $315 \mathrm{mg} / \mathrm{d}$ by 1 - to 6-month-old infants are safe, and that no consistent adverse effects in platelet function, lipid levels, in vivo oxidation parameters, glycaemic control or immune function have been observed in adults consuming up to $7.5 \mathrm{~g}$ $\mathrm{DHA} / \mathrm{d}^{(160)}$. Inuit ${ }^{(18,148)}$ and the many fish-eating populations in other countries, including Africa ${ }^{(34,35)}$, are living testimony of this thesis. AA is, however, invariably feared for its role in coagulation and inflammatory reactions. A human feeding study with $6 \mathrm{~g} \mathrm{AA/d}$ (supplemented as ethyl ester) was terminated because of a marked increase in in vitro platelet aggregation $^{(161)}$. In subsequent well-controlled studies, Nelson et al. ${ }^{(162)}$ observed no changes in blood coagulation, thrombotic tendencies or immune functions ${ }^{(163)}$, but also observed a small increase in neutrophil count and immune response to influenza vaccine ${ }^{(164)}$, together with increases in thromboxane, $\mathrm{PGI}_{2}{ }^{(165)}, \mathrm{PGE}_{2}$ and leukotriene $\mathrm{B}_{4}{ }^{(163)}$ in healthy male adults consuming $1.5 \mathrm{~g}$ AA for $50 \mathrm{~d}$. They attributed the near absence of changes in the immune functions tested to derive from the opposing effects of PG and thromboxanes. Recently, Kusumoto et al. ${ }^{(166)}$ showed that supplementation of $840 \mathrm{mg} \mathrm{AA} / \mathrm{d}$ for 4 weeks did not affect metabolic parameters or platelet function. Moreover, the 'proinflammatory' AA is also needed for the synthesis of AA-derived lipoxines, which are pro-resolving and mediate the switch to the synthesis of the anti-inflammatory resolvins and protectins synthesised from EPA and $\mathrm{DHA}^{(167)}$. It should finally be noted that all these studies were performed with high AA, low LCP $n-3$ supplements. In our models, the increase in EPA + DHA is more pronounced compared with the increase in AA (see ratio (EPA + DHA)/AA in Figs. 2 and 3), with increasing LCP intakes. Other studies relating AA with or without concomitant EPA + DHA intakes to eicosanoid production showed that dietary AA enhanced in vivo eicosanoid production ${ }^{(168)}$, while even low doses of AA were able to reverse EPA + DHA-induced decreases in $\mathrm{PGI}_{2}$ and thromboxane $\mathrm{A}_{2}$ production ${ }^{(169)}$. Although shortterm AA-rich meat diets did not affect platelet aggregation, thromboxane $\mathrm{B}_{2}, \mathrm{PGI}_{2}$ or thromboxane $\mathrm{A}_{2}$ production ${ }^{(170)}$, O'Dea et $a .^{(171)}$ showed a rise in bleeding time after the consumption of LA- and AA-rich meat and fish. Together, the health effects of AA are still controversial, and there is as yet insufficient evidence to decide whether high AA, with or without concurrent high LCP $n-3$ intakes, are harmless or beneficial $^{(144,172)}$, but high intakes of AA clearly need caution. However, it is likely that at high dietary AA and DHA intakes, the surpluses will for a great deal be used for retroconversion, energy generation or both, although to our knowledge no hard data are available in support of this notion.

\section{Limitations}

The outcome of our models should be viewed upon as indicative for the range of the dietary compositions of our ancestors, since we have obviously no hard data on their foraging strategies and the nutrient compositions of the plants and animals that they consumed. Our data rely on the comparability of the compositions of contemporary foods with the foods available in the Paleolithic and on the representativeness of the foods that have been analysed. Whether our earliest ancestors employed cooking remains controversial, but its employment would have increased the digestibility of certain plant foods and consequently the availability of certain nutrients. While for fish species an increasing amount of literature on energy density, macronutrient content and fatty acid composition is available, comparable literature on wild animals and plants is scarce or inaccessible. With respect to East African plant specimens, the literature provides even less information. For example, the AA contents of plants are derived from a single publication, and those analyses were not confirmed by MS. Despite the even higher AA content of seaweed and insects, the AA contents of many plant foods are probably lower, and their AA contents certainly warrant further studies. In other words, a better approximation of the Paleolithic diet would be possible when more complete information on fatty acids in African nuts, fruits, roots, bulbs, gums and tubers would become available. There is no evidence that our ancestors used fishing gear before 300000 years ago ${ }^{(10)}$. However, there is circumstantial evidence that fish up to $1 \mathrm{~m}$ in length were caught bare handed, when spawning during the rainy periods or when trapped in pools during drought ${ }^{(12)}$. Nevertheless, the current use of the fatty acid composition of East African fish might not be appropriate, and in reality might better be described by some combination of the fatty acid compositions of a variety of animals living in the landwater ecosystem, who ultimately receive their LCP from plankton. Apart from fish, however, we could not recover any data on the fatty acid composition of such African species. Taken together, an increasingly complex multidimensional model differentiating between African plant foods (seaweeds, 
nuts, seeds etc), land animals (all edible organs) and marine animals (fish, shellfish, eggs) and in which all separate intakes and nutrient compositions are varied within their most realistic ranges, would certainly improve the current estimates. Finally, due to differences in environmental circumstances, Paleolithic and modern humans might have had different benefits from the intake of fatty acids, such as AA. High AA intakes might confer unfavourable effects in Western societies, where morbidity and mortality stem mostly from chronic diseases with inflammation and thrombosis, but might have been favourable to Paleolithic humans who were mainly confronted with morbidity and mortality from infection and trauma. The latter suggests that AA might have conferred antagonistic pleiotrophy in the past.

\section{Conclusions}

We found that the macronutrient composition of the presumed Paleolithic diet averaged 25-29 en\% (range 8-35) from protein, 39-40 en\% (19-48) from carbohydrate and 30-39 en\% (20-72) from fat. These data imply that Paleolithic diets provided moderate-to-high protein and fat intakes, and moderate carbohydrate intakes. The fatty acid composition was moderate-to-high in MUFA and PUFA, but relatively high in SFA. The PUFA were notably high in ALA, LCP $n-3$ and LCP $n-6$, but low in LA, compared with the current Western intakes and recommendations. With the previous limitations in mind, the current data reflect the nutritional balance on, and selection pressure under which, our genome evolved. Our models reveal consistent differences between estimated Paleolithic macronutrient and fatty acid intakes and those found in contemporary Western diets as well as recommendations. Together with other human-caused environmental changes, these disparities are likely to play an important role in the aetiology of Western disease. For example, the dyslipidaemic effect of (hyper energetic) carbohydrates, the positive relation between protein intake, satiety and satiation as well as the many beneficial effects attributed to LCP suggest a beneficial role for the consumption of Paleolithic-like diets. These diets do not as much affect our life expectancy, but rather affect our years in good health. Interestingly, many of the dietary disparities are at present heavily debated, suggesting that both the approaches via intervention trials and evolutionary medicine identify critical dietary factors that are important to current Western diseases. We suggest that the present data represent a unique and powerful rationale for the design of future intervention studies.

\section{Acknowledgements}

None of the authors had any financial or personal conflict of interest to declare. No funding was received for this study. The authors' responsibilities were as follows: R. S. K. and M. F. L. collected all the literature data for the reference database. Together with D. A. J. D.-B., R. S. K. and M. F. L. composed the first version of the manuscript. After finishing the first version, the other authors were asked to contribute to the paper, for their longstanding and previous experience on the same subject. We thank both anonymous reviewers and S. C. Cunnane for their thorough review of our manuscript.

\section{Units}

'Plant' refers to any edible component from the kingdom of Plantae and Fungi, while 'animal' refers to edible components from the kingdom of Animalia. For meat consumption, only $50 \mathrm{~g} \%$ of the total carcass weight was considered as edible material $^{(62)}$. The weights of the consumed organs are therefore presented as a percentage of the total edible material, i.e. $3.8 \mathrm{~g} \%$ for the liver, rather than as a percentage of total carcass weight (i.e. $1.9 \mathrm{~g} \%$ for the liver). Plant food and fish were considered to be consumed completely. Fat contents are consistently presented as $\mathrm{g} / 100 \mathrm{~g}$ edible material $(\mathrm{g} \%)$. Fat contents refer either to the specific fat $\%$ of a particular organ (e.g. the brain) or to the fat $\%$ of all edible material (i.e. the fat $\%$ of all combined edible material, including lean meat, brain, liver, bone marrow and adipose tissue). Plant/animal and meat/fish ratios and ratios between skeletal muscle, brain, bone marrow, liver and adipose tissue are given in en\%. Fatty acid compositions are given in $\mathrm{g} / 100 \mathrm{~g}$ fatty acids (g/100 g, g\%). Organ weight contributions to selectively and non-selectively consumed meat are presented as $\mathrm{g} / 100 \mathrm{~g}$ meat.

\section{References}

1. Eaton SB \& Konner M (1985) Paleolithic nutrition. A consideration of its nature and current implications. $N$ Engl $J$ Med 312, 283-289.

2. Eaton SB \& Eaton SB III (2000) Paleolithic vs. modern diets selected pathophysiological implications. Eur J Nutr 39, 67-70.

3. Eaton SB, Eaton SB III, Konner MJ, et al. (1997) Paleolithic nutrition revisited: a twelve-year retrospective on its nature and implications. Eur J Clin Nutr 51, 207-216.

4. Hill K, Hurtado AM \& Walker RS (2007) High adult mortality among Hiwi hunter-gatherers: implications for human evolution. J Hum Evol 52, 443-454.

5. Volek JS, Fernandez ML, Feinman RD, et al. (2008) Dietary carbohydrate restriction induces a unique metabolic state positively affecting atherogenic dyslipidemia, fatty acid partitioning, and metabolic syndrome. Prog Lipid Res 47, 307-318.

6. Eaton SB, Eaton SB III, Konner MJ, et al. (1996) An evolutionary perspective enhances understanding of human nutritional requirements. $J$ Nutr 126, 1732-1740.

7. Bensinger SJ \& Tontonoz P (2008) Integration of metabolism and inflammation by lipid-activated nuclear receptors. Nature 454, 470-477.

8. Chawla A, Repa JJ, Evans RM, et al. (2001) Nuclear receptors and lipid physiology: opening the X-files. Science 294, 1866-1870.

9. Broadhurst CL, Cunnane SC \& Crawford MA (1998) Rift Valley lake fish and shellfish provided brain-specific nutrition for early Homo. Br J Nutr 79, 3-21.

10. Erlandson JM (2001) The archaeology of aquatic adaptations: paradigms for a new millennium. J Archaeol Res 9, 287-350.

11. Broadhurst CL, Wang Y, Crawford MA, et al. (2002) Brainspecific lipids from marine, lacustrine, or terrestrial food resources: potential impact on early African Homo sapiens. Comp Biochem Physiol B Biochem Mol Biol 131, 653-673.

12. Stewart KM (1994) Early hominid utilization of fish resources and implications for seasonality and behavior. J Hum Evol 27, 229-245.

13. Stringer C (2000) Palaeoanthropology - Coasting out of Africa. Nature 405, 24-27.

14. Wang S, Lewis CM, Jakobsson M, et al. (2007) Genetic variation and population structure in native Americans. PLoS Genet 3 , e185. 
15. Crawford MA (2002) Cerebral evolution. Nutr Health 16, 29-34.

16. Cunnane SC (2005) Origins and evolution of the Western diet: implications of iodine and seafood intakes for the human brain. Am J Clin Nutr 82, 483-484.

17. de Lorgeril M, Salen P, Martin JL, et al. (1999) Mediterranean diet, traditional risk factors, and the rate of cardiovascular complications after myocardial infarction: final report of the Lyon Diet Heart Study. Circulation 99, 779-785.

18. Feskens EJ \& Kromhout D (1993) Epidemiologic studies on Eskimos and fish intake. Ann N Y Acad Sci 683, 9-15.

19. Marchioli R, Barzi F, Bomba E, et al. (2002) Early protection against sudden death by $n-3$ polyunsaturated fatty acids after myocardial infarction: time-course analysis of the results of the Gruppo Italiano per lo Studio della Sopravvivenza nell'Infarto Miocardico (GISSI)-Prevenzione. Circulation 105, 1897-1903.

20. Hibbeln JR (2002) Seafood consumption, the DHA content of mothers' milk and prevalence rates of postpartum depression: a cross-national, ecological analysis. J Affect Disord 69, 15-29.

21. Hibbeln JR (2009) Depression, suicide and deficiencies of omega-3 essential fatty acids in modern diets. World Rev Nutr Diet 99, 17-30.

22. McCann JC \& Ames BN (2005) Is docosahexaenoic acid, an n-3 long-chain polyunsaturated fatty acid, required for development of normal brain function? An overview of evidence from cognitive and behavioral tests in humans and animals. Am J Clin Nutr 82, 281-295.

23. Plourde M \& Cunnane SC (2007) Extremely limited synthesis of long chain polyunsaturates in adults: implications for their dietary essentiality and use as supplements. Appl Physiol Nutr Metab 32, 619-634.

24. Caspi A, Williams B, Kim-Cohen J, et al. (2007) Moderation of breastfeeding effects on the IQ by genetic variation in fatty acid metabolism. Proc Natl Acad Sci U S A 104, $18860-18865$.

25. Eaton SB (1992) Humans, lipids and evolution. Lipids 27, $814-820$

26. Eaton SB, Eaton SB III, Sinclair AJ, et al. (1998) Dietary intake of long-chain polyunsaturated fatty acids during the paleolithic. World Rev Nutr Diet 83, 12-23.

27. Cordain L, Miller JB, Eaton SB, et al. (2000) Plantanimal subsistence ratios and macronutrient energy estimations in worldwide hunter-gatherer diets. Am J Clin Nutr 71, 682-692.

28. Cordain L, Watkins BA \& Mann NJ (2001) Fatty acid composition and energy density of foods available to African hominids. Evolutionary implications for human brain development. World Rev Nutr Diet 90, 144-161.

29. Ulijaszek SJ (2002) Human eating behaviour in an evolutionary ecological context. Proc Nutr Soc 61, 517-526.

30. Goldstone AP, de Hernandez CG, Beaver JD, et al. (2009) Fasting biases brain reward systems towards high-calorie foods. Eur J Neurosci 30, 1625-1635.

31. Hawkes K, O'Connell JF, Jones NG, et al. (1998) Grandmothering, menopause, and the evolution of human life histories. Proc Natl Acad Sci U S A 95, 1336-1339.

32. Sear R, Mace R \& McGregor IA (2000) Maternal grandmothers improve nutritional status and survival of children in rural Gambia. Proc Biol Sci 267, 1641-1647.

33. USDA (2008) National Nutrient Database for Standard Reference. http://www.nal.usda.gov/fnic/foodcomp/search (accessed 15 August 2008).

34. Kuipers RS, Fokkema MR, Smit EN, et al. (2005) High contents of both docosahexaenoic and arachidonic acids in milk of women consuming fish from lake Kitangiri (Tanzania): targets for infant formulae close to our ancient diet? Prostaglandins Leukot Essent Fatty Acids 72, 279-288.
35. Kuipers RS, Smit EN, van der Meulen J, et al. (2007) Milk in the island of Chole [Tanzania] is high in lauric, myristic, arachidonic and docosahexaenoic acids, and low in linoleic acid reconstructed diet of infants born to our ancestors living in tropical coastal regions. Prostaglandins Leukot Essent Fatty Acids 76, 221-233.

36. Stewart JH (1968) Causal factors and processes in the evolution of pre-farming societies. In Man the Hunter, pp. 321-334 [RB Lee and I DeVore, editors]. New York: Aldine Publishing Company.

37. Lee RB (1968) What hunters do for a living, or, how to make out on scarce resources. In Man the Hunter, pp. 30-48 [RB Lee and I DeVore, editors]. New York: Aldine Publishing Company.

38. Murdock GV (1967) Ethnographic Atlas. Pittsburgh, PA: University of Pittsburgh Press.

39. Woodburn J (1968) An introduction to Hadza ecology. In Man the Hunter, pp. 49-55 [RB Lee and I DeVore, editors]. New York: Aldine Publishing Company.

40. Roberts MB, Stringer CB \& Parfitt SA (1994) A hominid tibia from Middle Pleistocene sediments at Boxgrove, UK. Nature 369, 311-313.

41. Leonard WR \& Robertson ML (1992) Nutritionalrequirements and human-evolution - a bioenergetics model. Am J Hum Biol 4, 179-195.

42. Cordain L, Gotshall RW, Eaton SB, et al. (1998) Physical activity, energy expenditure and fitness: an evolutionary perspective. Int J Sports Med 19, 328-335.

43. Eaton SB \& Eaton SB (2003) An evolutionary perspective on human physical activity: implications for health. Comp Biochem Physiol A Mol Integr Physiol 136, 153-159.

44. Blumenschine RJ \& Cavallo JA (1992) Scavenging and human-evolution. Sci Am 267, 90-96.

45. Blumenschine RJ \& Madrigal TC (1993) Variability in long-bone marrow yields of east-African ungulates and its zooarchaeological implications. $J$ Archaeol Sci 20, 555-587.

46. Cordain L, Watkins BA, Florant GL, et al. (2002) Fatty acid analysis of wild ruminant tissues: evolutionary implications for reducing diet-related chronic disease. Eur J Clin Nutr 56, $181-191$

47. Lupo KD (1998) Experimentally derived extraction rates for marrow: implications for body past exploitation strategies of Plio-Pleistocene hominid scavengers. J Archaeol Sci 25, 657-675.

48. Bunn HT \& Ezzo JA (1993) Hunting and scavenging by Pliopleistocene hominids - nutritional constraints, archaeological patterns, and behavioral-implications. J Archaeol Sci 20, 365-398.

49. Brand-Miller JC \& Holt SH (1998) Australian aboriginal plant foods: a consideration of their nutritional composition and health implications. Nutr Res Rev 11, 5-23.

50. Guil JL, Torija ME, Gimenez JJ, et al. (1996) Identification of fatty acids in edible wild plants by gas chromatography. J Chromatogr A 719, 229-235.

51. Ezeagu IE, Petzke KJ, Lange E, et al. (1998) Fat content and fatty acid composition of oils extracted from selected wildgathered tropical plant seeds from Nigeria. J Am Oil Chem Soc 75, 1031-1035.

52. Freiberger CE, Vanderjagt DJ, Pastuszyn A, et al. (1998) Nutrient content of the edible leaves of seven wild plants from Niger. Plant Foods Hum Nutr 53, 57-69.

53. Rocquelin G, Tapsoba S, Mbemba F, et al. (1998) Lipid content and fatty acid composition in foods commonly consumed by nursing Congolese women: incidences on their essential fatty acid intakes and breast milk fatty acids. Int $J$ Food Sci Nutr 49, 343-352. 
54. Vincent AS (1985) Plant foods in savanna environments: a preliminary report of tubers eaten by the Hadza of Northern Tanzania. World Archaeol 17, 131-148.

55. Wehmeyer AS, Lee RB \& Whiting M (1969) The nutrient composition and dietary importance of some vegetable foods eaten by the Kung Bushmen. S Afr Med $J$ 43, $1529-1530$.

56. Bhaskar N, Kinami T, Miyashita K, et al. (2004) Occurrence of conjugated polyenoic fatty acids in seaweeds from the Indian Ocean. Zeitschrift fur Naturforschung $C-J$ Biosci 59, 310-314.

57. Dembitsky VM, Pechenkinashubina EE \& Rozentsvet OA (1991) Glycolipids and fatty-acids of some seaweeds and marine grasses from the Black-Sea. Phytochemistry 30, 2279-2283.

58. Khotimchenko SV (1991) Fatty-acid composition of 7 Sargassum species. Phytochemistry 30, 2639-2641.

59. Norziah MH \& Ching CY (2000) Nutritional composition of edible seaweed Gracilaria changgi. Food Chem 68, 69-76.

60. Oyarzun SE, Crawshaw JG \& Valverde E (1996) Nutrition of the Tamandua: I. Nutrient composition of termites (Nasutitermes spp.) and stomach contents from wild Tamanduas (Tamandua tetradactyla). Zoo Biol 15, 509-524.

61. Stanley-Samuelson DW \& Dadd RH (1983) Long-chain polyunsaturated fatty acids: patterns of occurence in insects. Insect Biochem 13, 549-558.

62. Ledger HP (1969) Body composition as a basis for a comparative study of some East African mammals. Symp Zool Soc Lond 21, 280-310.

63. Crawford MA (1968) Fatty-acid ratios in free-living and domestic animals. Possible implications for atheroma. Lancet 1, 1329-1333.

64. Crawford MA, Gale MM \& Woodford MH (1969) Linoleic acid and linolenic acid elongation products in muscle tissue of Sncerus caffer and other ruminant species. Biochem $J$ 115, 25-27.

65. Crawford MA, Gale MM \& Woodford MH (1970) Muscle and adipose tissue lipids of warthog, Phacochoerus aethiopicus. Int J Biochem 1, 654-658.

66. Crawford MA, Gale MM, Woodford MH, et al. (1970) Comparative studies on fatty acid composition of wild and domestic meats. Int J Biochem 1, 295.

67. Crawford MA \& Woodford MH (1971) Fatty-acid composition in liver, aorta, skeletal and heart-muscle of 2 free-living ruminants. Int J Biochem 2, 493.

68. Duncan WR \& Garton GA (1968) The fatty acid composition and intramolecular structure of triglycerides from adipose tissue of the hippopotamus and the African elephant. Comp Biochem Physiol 25, 319-325.

69. Naughton JM, O'Dea K \& Sinclair AJ (1986) Animal foods in traditional Australian aboriginal diets: polyunsaturated and low in fat. Lipids 21, 684-690.

70. Sinclair AJ, Slattery WJ \& O'Dea K (1982) The analysis of polyunsaturated fatty acids in meat by capillary gas liquid chromatography. J Sci Fd Agric 33, 776.

71. Ailhaud G, Massiera F, Weill P, et al. (2006) Temporal changes in dietary fats: role of $n-6$ polyunsaturated fatty acids in excessive adipose tissue development and relationship to obesity. Prog Lipid Res 45, 203-236.

72. Pauletto P, Puato M, Angeli MT, et al. (1996) Blood pressure, serum lipids, and fatty acids in populations on a lake-fish diet or on a vegetarian diet in Tanzania. Lipids 31, S309-S312.

73. Ackman RG (1989) Nutritional composition of fats in seafoods. Prog Food Nutr Sci 13, 161-289.

74. Rudman D, DiFulco TJ, Galambos JT, et al. (1973) Maximal rates of excretion and synthesis of urea in normal and cirrhotic subjects. J Clin Invest 52, 2241-2249.
75. Lieb CW (1929) The effects on human beings of a twelve months' exclusive meat diet. JAMA 93, 20-22.

76. Speth JD \& Spielmann KA (1983) Energy-source, proteinmetabolism, and hunter gatherer subsistence strategies. J Anthropol Archaeol 2, 1-31.

77. Burr GO \& Burr MM (1930) On the nature and rôle of the fatty acids essential in nutrition. $J$ Biol Chem 86, 587-621.

78. Cuthbertson WF (1976) Essential fatty acid requirements in infancy. Am J Clin Nutr 29, 559-568.

79. Holman RT (1970) Biological activities of and requirements for polyunsaturated acids. Progr Chem Fats Other Lipids 9, 607-682.

80. Givens ID \& Gibbs RA (2008) Current intakes of EPA and DHA in European populations and the potential of animalderived foods to increase them. Proc Nutr Soc 67, 273-280.

81. Ervin RB, Wright JD, Wang CY, et al. (2004) Dietary intake of fats and fatty acids for the United States population: 1999-2000. Adv Data 1-6.

82. White TD, Ambrose SH, Suwa G, et al. (2009) Macrovertebrate paleontology and the Pliocene habitat of Ardipithecus ramidus. Science 326, 87-93.

83. Washburn SL \& Lancaster CS (1968) The Evolution of Hunting. In Man the Hunter, pp. 293-303 [RB Lee and I DeVore, editors]. New York: Aldine Publishing Company.

84. Sailer LD, Gaulin SC, Voster JS, et al. (1985) Measuring the relationship between diatary quality and body size in primates. Primates 26, 14-27.

85. Wells JC (2006) The evolution of human fatness and susceptibility to obesity: an ethological approach. Biol Rev Camb Philos Soc 81, 183-205.

86. Cunnane SC \& Crawford MA (2003) Survival of the fattest: fat babies were the key to evolution of the large human brain. Comp Biochem Physiol A Mol Integr Physiol 136, 17-26.

87. Leonard WR, Robertson ML, Snodgrass JJ, et al. (2003) Metabolic correlates of hominid brain evolution. Comp Biochem Physiol A Mol Integr Physiol 136, 5-15.

88. Milton K (2003) The critical role played by animal source foods in human (Homo) evolution. J Nutr 133, 3886S-3892S.

89. Aiello LC \& Wheeler P (1995) The expensive-tissue hypothesis - the brain and the digestive-system in human and primate evolution. Curr Anthropol 36, 199-221.

90. Rao JS, Ertley RN, DeMar JC Jr, et al. (2007) Dietary $n-3$ PUFA deprivation alters expression of enzymes of the arachidonic and docosahexaenoic acid cascades in rat frontal cortex. Mol Psychiatry 12, 151-157.

91. Hsieh AT \& Brenna JT (2009) Dietary docosahexaenoic acid but not arachidonic acid influences central nervous system fatty acid status in baboon neonates. Prostaglandins Leukot Essent Fatty Acids 81, 105-110.

92. Makrides M, Neumann MA, Byard RW, et al. (1994) Fatty acid composition of brain, retina, and erythrocytes in breast- and formula-fed infants. Am J Clin Nutr 60, 189-194.

93. van Goor SA, Dijck-Brouwer DA, Fokkema MR, et al. (2008) Maternal and fetal brain contents of docosahexaenoic acid (DHA) and arachidonic acid (AA) at various essential fatty acid (EFA), DHA and AA dietary intakes during pregnancy in mice. Prostaglandins Leukot Essent Fatty Acids 78, 159-169.

94. Koletzko B, Lien E, Agostoni C, et al. (2008) The roles of long-chain polyunsaturated fatty acids in pregnancy, lactation and infancy: review of current knowledge and consensus recommendations. J Perinat Med 36, 5-14.

95. Isaac B (1987) Throwing and human evolution. Afr Archaeol $\operatorname{Rev~5,3-17.~}$

96. Sargent JR (1997) Fish oils and human diet. Br J Nutr 78, Suppl. 1, S5-13.

97. Simopoulos AP (2008) The importance of the omega-6/omega3 fatty acid ratio in cardiovascular disease and other chronic diseases. Exp Biol Med (Maywood) 233, 674-688. 
98. Richards MP, Schulting RJ \& Hedges RE (2003) Archaeology: sharp shift in diet at onset of Neolithic. Nature 425, 366.

99. CDC (2004) Trends in Intake of Energy and Macronutrients United States, 1971-2000. http://www.cdc.gov/mmwrhtml/ mm5304a3.htm (accessed 15 August 2008).

100. Institute of Medicine (2005) Dietary reference intakes for energy, carbohydrate, fiber, fat, fatty acids, cholesterol, protein, and amino acids (2002/2005). http://www.nap.edu (accessed 15 August 2008).

101. Smit E, Nieto FJ, Crespo CJ, et al. (1999) Estimates of animal and plant protein intake in US adults: results from the Third National Health and Nutrition Examination Survey, 1988-1991. J Am Diet Assoc 99, 813-820.

102. Frassetto L, Morris RC Jr, Sellmeyer DE, et al. (2001) Diet, evolution and aging - the pathophysiologic effects of the post-agricultural inversion of the potassium-to-sodium and base-to-chloride ratios in the human diet. Eur J Nutr 40, 200-213.

103. Beasley JM, Ange BA, Anderson CA, et al. (2009) Associations between macronutrient intake and self-reported appetite and fasting levels of appetite hormones: results from the Optimal Macronutrient Intake Trial to Prevent Heart Disease. Am J Epidemiol 169, 893-900.

104. Gardner CD, Kiazand A, Alhassan S, et al. (2007) Comparison of the Atkins, Zone, Ornish, and LEARN diets for change in weight and related risk factors among overweight premenopausal women: the A TO Z Weight Loss Study: a randomized trial. JAMA 297, 969-977.

105. Alhassan S, Kim S, Bersamin A, et al. (2008) Dietary adherence and weight loss success among overweight women: results from the A TO $\mathrm{Z}$ weight loss study. Int $J$ Obes (Lond) 32, 985-991.

106. Batterham RL, Heffron H, Kapoor S, et al. (2006) Critical role for peptide YY in protein-mediated satiation and body-weight regulation. Cell Metab 4, 223-233.

107. Westerterp-Plantenga MS, Nieuwenhuizen A, Tome D, et al. (2009) Dietary protein, weight loss, and weight maintenance. Апnи Rev Nutr 29, 21-41.

108. Rolls BJ (2009) The relationship between dietary energy density and energy intake. Physiol Behav 97, 609-615.

109. Osterdahl M, Kocturk T, Koochek A, et al. (2008) Effects of a short-term intervention with a paleolithic diet in healthy volunteers. Eur J Clin Nutr 62, 682-685.

110. Jonsson T, Granfeldt Y, Ahren B, et al. (2009) Beneficial effects of a Paleolithic diet on cardiovascular risk factors in type 2 diabetes: a randomized cross-over pilot study. Cardiovasc Diabetol 8, 35.

111. Lindeberg S, Jonsson T, Granfeldt Y, et al. (2007) A Palaeolithic diet improves glucose tolerance more than a Mediterranean-like diet in individuals with ischaemic heart disease. Diabetologia 50, 1795-1807.

112. Hunt JR, Johnson LK \& Fariba Roughead ZK (2009) Dietary protein and calcium interact to influence calcium retention: a controlled feeding study. Am J Clin Nutr 89, $1357-1365$

113. Barclay AW, Petocz P, McMillan-Price J, et al. (2008) Glycemic index, glycemic load, and chronic disease risk - a meta-analysis of observational studies. Am J Clin Nutr 87, 627-637.

114. Niwano Y, Adachi T, Kashimura J, et al. (2009) Is glycemic index of food a feasible predictor of appetite, hunger, and satiety? J Nutr Sci Vitaminol (Tokyo) 55, 201-207.

115. Last AR \& Wilson SA (2006) Low-carbohydrate diets. Am Fam Physician 73, 1942-1948.

116. Frassetto LA, Schloetter M, Mietus-Synder M, et al. (2009) Metabolic and physiologic improvements from consuming a paleolithic, hunter-gatherer type diet. Eur J Clin Nutr 63, 947-955.
117. Kunsman JE, Collins MA, Field RA, et al. (1981) Cholesterol content of beef bone-marrow and mechanically deboned meat. J Food Sci 46, 1785-1788.

118. Klein CJ (2006) The scientific evidence and approach taken to establish guidelines for cholesterol intake in Australia, Canada, the United Kingdom, and the United States. Executive summary. http://www.LSRO.org (accessed 15 August 2008).

119. O'Keefe JH Jr, Cordain L, Harris WH, et al. (2004) Optimal low-density lipoprotein is 50 to $700 \mathrm{mg} / \mathrm{l}$ : lower is better and physiologically normal. $J$ Am Coll Cardiol 43, 2142-2146.

120. Mann GV, Roels OA, Price DL, et al. (1962) Cardiovascular disease in African Pygmies. A survey of the health status, serum lipids and diet of Pygmies in Congo. J Chron Dis 15, 341-371.

121. Mann GV, Shaffer RD \& Rich A (1965) Physical fitness and immunity to heart-disease in Masai. Lancet 2, 1308-1310.

122. Clarke R, Frost C, Collins R, et al. (1997) Dietary lipids and blood cholesterol: quantitative meta-analysis of metabolic ward studies. $B M J$ 314, 112-117.

123. Mente A, de Koning L, Shannon HS, et al. (2009) A systematic review of the evidence supporting a causal link between dietary factors and coronary heart disease. Arch Intern Med 169, 659-669.

124. Mozaffarian D, Rimm EB \& Herrington DM (2004) Dietary fats, carbohydrate, and progression of coronary atherosclerosis in postmenopausal women. Am J Clin Nutr 80, 1175-1184.

125. Mensink RP, Zock PL, Kester AD, et al. (2003) Effects of dietary fatty acids and carbohydrates on the ratio of serum total to HDL cholesterol and on serum lipids and apolipoproteins: a meta-analysis of 60 controlled trials. Am J Clin Nutr 77, 1146-1155.

126. Davis JE, Gabler NK, Walker-Daniels J, et al. (2009) The c-Jun N-terminal kinase mediates the induction of oxidative stress and insulin resistance by palmitate and toll-like receptor 2 and 4 ligands in 3T3-L1 adipocytes. Horm Metab Res 41, $523-530$

127. Schaeffler A, Gross P, Buettner R, et al. (2009) Fatty acid-induced induction of Toll-like receptor-4/nuclear factorkappaB pathway in adipocytes links nutritional signalling with innate immunity. Immunology 126, 233-245.

128. Hudgins LC, Parker TS, Levine DM, et al. (2003) A single intravenous dose of endotoxin rapidly alters serum lipoproteins and lipid transfer proteins in normal volunteers. J Lipid Res $\mathbf{4 4}$, 1489-1498.

129. Zhou BF, Stamler J, Dennis B, et al. (2003) Nutrient intakes of middle-aged men and women in China, Japan, United Kingdom, and United States in the late 1990s: the INTERMAP study. J Hum Hypertens 17, 623-630.

130. Matalas AL (2006) Disparities within traditional Mediterranean food patterns: an historical approach of the Greek diet. Int J Food Sci Nutr 57, 529-536.

131. Tunstall-Pedoe H, Kuulasmaa K, Mahonen M, et al. (1999) Contribution of trends in survival and coronary-event rates to changes in coronary heart disease mortality: 10-year results from 37 WHO MONICA project populations. Monitoring trends and determinants in cardiovascular disease. Lancet 353, $1547-1557$

132. Sugano M \& Hirahara F (2000) Polyunsaturated fatty acids in the food chain in Japan. Am J Clin Nutr 71, 189S-196S.

133. Berglund L, Lefevre M, Ginsberg HN, et al. (2007) Comparison of monounsaturated fat with carbohydrates as a replacement for saturated fat in subjects with a high metabolic risk profile: studies in the fasting and postprandial states. Am $J$ Clin Nutr 86, 1611-1620.

134. Sanders TA (2009) DHA status of vegetarians. Prostaglandins Leukot Essent Fatty Acids 81, 137-141. 
135. Cunnane SC, Ryan MA, Lin YH, et al. (2006) Suckling rats actively recycle carbon from alpha-linolenate into newly synthesized lipids even during extreme dietary deficiency of n-3 polyunsaturates. Pediatr Res 59, 107-110.

136. Cunnane SC (2003) Problems with essential fatty acids: time for a new paradigm? Prog Lipid Res 42, 544-568.

137. Stark AH, Crawford MA \& Reifen R (2008) Update on alphalinolenic acid. Nutr Rev 66, 326-332.

138. Zhao G, Etherton TD, Martin KR, et al. (2007) Dietary alphalinolenic acid inhibits proinflammatory cytokine production by peripheral blood mononuclear cells in hypercholesterolemic subjects. Am J Clin Nutr 85, 385-391.

139. Djousse L, Arnett DK, Carr JJ, et al. (2005) Dietary linolenic acid is inversely associated with calcified atherosclerotic plaque in the coronary arteries: the National Heart, Lung, and Blood Institute Family Heart Study. Circulation 111, 2921-2926.

140. Harris WS, Mozaffarian D, Rimm E, et al. (2009) Omega-6 fatty acids and risk for cardiovascular disease: a science advisory from the American Heart Association Nutrition Subcommittee of the Council on Nutrition, Physical Activity, and Metabolism; Council on Cardiovascular Nursing; and Council on Epidemiology and Prevention. Circulation 119, 902-907.

141. Ramakers JD, Mensink RP, Verstege MI, et al. (2008) An arachidonic acid-enriched diet does not result in more colonic inflammation as compared with fish oil- or oleic acid-enriched diets in mice with experimental colitis. Br J Nutr 100, 347-354.

142. Hart AR (2009) Linoleic acid, a dietary $n-6$ polyunsaturated fatty acid, and the aetiology of ulcerative colitis - a European prospective cohort study. Gut.

143. Wolfe AR, Ogbonna EM, Lim S, et al. (2009) Dietary linoleic and oleic fatty acids in relation to severe depressed mood: 10 years follow-up of a national cohort. Prog Neuropsychopharmacol Biol Psychiatry 33, 972-977.

144. Calder PC (2010) The 2008 ESPEN Sir David Cuthbertson Lecture: fatty acids and inflammation - from the membrane to the nucleus and from the laboratory bench to the clinic. Clin Nutr 29, 5-12.

145. Yam D, Eliraz A \& Berry EM (1996) Diet and disease - the Israeli paradox: possible dangers of a high omega- 6 polyunsaturated fatty acid diet. Isr J Med Sci 32, 1134-1143.

146. Angela Liou Y \& Innis SM (2009) Dietary linoleic acid has no effect on arachidonic acid, but increases $n-6$ eicosadienoic acid, and lowers dihomo-gamma-linolenic and eicosapentaenoic acid in plasma of adult men. Prostaglandins Leukot Essent Fatty Acids 80, 201-206.

147. Feskens EJ \& Kromhout D (1993) Epidemiologic studies on Eskimos and fish intake. Ann N Y Acad Sci 683, 9-15.

148. Innis SM \& Kuhnlein HV (1988) Long-chain $n$-3 fatty acids in breast milk of Inuit women consuming traditional foods. Early Hum Dev 18, 185-189.

149. Crawford MA, Bloom M, Broadhurst CL, et al. (1999) Evidence for the unique function of docosahexaenoic acid during the evolution of the modern hominid brain. Lipids 34, S39-S47.

150. Mozaffarian D \& Rimm EB (2006) Fish intake, contaminants, and human health: evaluating the risks and the benefits. JAMA 296, 1885-1899.

151. Psota TL, Gebauer SK \& Kris-Etherton P (2006) Dietary omega-3 fatty acid intake and cardiovascular risk. Am J Cardiol 98, 3i-18i.

152. Astorg P, Arnault N, Czernichow S, et al. (2004) Dietary intakes and food sources of $n-6$ and $n-3$ PUFA in French adult men and women. Lipids 39, 527-535.
153. Xie L \& Innis SM (2008) Genetic variants of the FADS1 FADS2 gene cluster are associated with altered $(n-6)$ and $(n-3)$ essential fatty acids in plasma and erythrocyte phospholipids in women during pregnancy and in breast milk during lactation. J Nutr 138, 2222-2228.

154. Collins FD, Sinclair AJ, Royle JP, et al. (1971) Plasma lipids in human linoleic acid deficiency. Nutr Metab 13, 150-167.

155. Holman RT, Johnson SB \& Hatch TF (1982) A case of human linolenic acid deficiency involving neurological abnormalities. A J Clin Nutr 35, 617-623.

156. Mead JF (1960) The Metabolism of the polyunsaturated fatty acids. Am J Clin Nutr 8, 55-61.

157. Hansen HS, Jensen B \& Wettstein-Knowles P (1986) Apparent in vivo retroconversion of dietary arachidonic to linoleic acid in essential fatty acid-deficient rats. Biochim Biophys Acta 878, 284-287.

158. Conquer JA \& Holub BJ (1997) Dietary docosahexaenoic acid as a source of eicosapentaenoic acid in vegetarians and omnivores. Lipids 32, 341-345.

159. Le HD, Meisel JA, de Meijer VE, et al. (2009) The essentiality of arachidonic acid and docosahexaenoic acid. Prostaglandins Leukot Essent Fatty Acids 81, 165-170.

160. Lien EL (2009) Toxicology and safety of DHA. Prostaglandins Leukot Essent Fatty Acids 81, 125-132.

161. Seyberth HW, Oelz O, Kennedy T, et al. (1975) Increased arachidonate in lipids after administration to man: effects on prostaglandin biosynthesis. Clin Pharmacol Ther 18, 521-529.

162. Nelson GJ, Schmidt PC, Bartolini G, et al. (1997) The effect of dietary arachidonic acid on platelet function, platelet fatty acid composition, and blood coagulation in humans. Lipids 32, 421-425.

163. Kelley DS, Taylor PC, Nelson GJ, et al. (1998) Arachidonic acid supplementation enhances synthesis of eicosanoids without suppressing immune functions in young healthy men. Lipids 33, 125-130.

164. Kelley DS, Taylor PC, Nelson GJ, et al. (1997) Effects of dietary arachidonic acid on human immune response. Lipids 32, 449-456.

165. Ferretti A, Nelson GJ, Schmidt PC, et al. (1997) Increased dietary arachidonic acid enhances the synthesis of vasoactive eicosanoids in humans. Lipids 32, 435-439.

166. Kusumoto A, Ishikura Y, Kawashima H, et al. (2007) Effects of arachidonate-enriched triacylglycerol supplementation on serum fatty acids and platelet aggregation in healthy male subjects with a fish diet. Br J Nutr 98, 626-635.

167. Serhan CN (2008) Systems approach with inflammatory exudates uncovers novel anti-inflammatory and pro-resolving mediators. Prostaglandins Leukot Essent Fatty Acids 79, 157-163.

168. Whelan J, Li B \& Birdwell C (1997) Dietary arachidonic acid increases eicosanoid production in the presence of equal amounts of dietary eicosapentaenoic acid. Adv Exp Med Biol 400B, 897-904.

169. Sanigorski AJ, Sinclair AJ \& Hamazaki T (1996) Platelet and aorta arachidonic and eicosapentaenoic acid levels and in vitro eicosanoid production in rats fed high-fat diets. Lipids 31, 729-735.

170. Mann N, Sinclair A, Pille M, et al. (1997) The effect of short-term diets rich in fish, red meat, or white meat on thromboxane and prostacyclin synthesis in humans. Lipids 32, 635-644.

171. O'Dea K \& Sinclair AJ (1985) The effects of low-fat diets rich in arachidonic acid on the composition of plasma fatty acids and bleeding time in Australian aborigines. J Nutr Sci Vitaminol (Tokyo) 31, 441-453.

172. Calder PC (2009) Polyunsaturated fatty acids and inflammatory processes: new twists in an old tale. Biochimie 91, 791-795. 